\title{
The geographical distribution of soil elements determines the boundaries of the Daodi-zone of medicinal plant (Ligusticum chuanxiong Hort.)
}

5 Hongyang Lv $\mathrm{Lv}^{1,2} \dagger$; Hai Wang ${ }^{1,2,3} \uparrow$; Qian Fang ${ }^{1,2} \uparrow$; Lei Kang ${ }^{1,2}$; Guiqi Han ${ }^{1,3}$; Xiaorui Zhang ${ }^{1,2}$; Qin $\mathrm{Si}^{3}$ Dongmei $\mathrm{He}^{1,2,4 *}$; Zhuyun Yan ${ }^{1,2^{*}}$

1.State Key Laboratory of Characteristic Chinese Medicine Resources in Southwest China, Chengdu University of Traditional Chinese Medicine, Chengdu,611137, People's Republic of China

2.Pharmacy College, Chengdu University of Traditional Chinese Medicine; The Ministry of Education Key Laboratory of Standardization of Chinese Herbal Medicine; Key Laboratory of Systematic Research, Development and Utilization of Chinese Medicine Resources in Sichuan Province-Key Laboratory Breeding Base of Co-founded by Sichuan Province and MOST

3.College of Medical Technology, Chengdu University of Traditional Chinese Medicine, Chengdu, 611137, People's Republic of China

4.Center for Post-doctoral research, National Resource Center for Chinese Materia Medica, China Academy of Chinese Medical Sciences, State Key Laboratory Breeding Base of Dao-di Herbs, Beijing 100700, China.

Correspondence to: Hedongmei (hedongmei@cdutcm.edu.cn)

Abstract. Understanding the boundary of plants' best production zone is of great significance to the rational introduction cultivation. We set up 9 sample points in the center-zone and 28 sample points extending eastward along the longitude. Then, we were collecting the bulk soil of L.chuanxiong, testing soil properties and elements. Later, a multi-point cultivation test was carried out on L.chuanxiong, the content of elements in the plant measured by ICP-MS, and HPLC detected the active ingredients. Based on hierarchical clustering and PCA analysis, the study zone's soil element was divided into three groups. In the L.chuanxiong cultivation experiments, we found Ligustilide in rhizomes was positively related to $\mathrm{Se}$ and $\mathrm{Sr}$ and negatively related to $\mathrm{Mn}$ and the chemical elements. This study successfully verified that the medicinal plant's Daodi-zone has a natural boundary, and L.chuanxiong's Daodi-zone may be from east of Dujiangyan to the west edge of Longquan, rich in $\mathrm{Na}, \mathrm{Mg}, \mathrm{K}$, and Low $\mathrm{Mn}$ is the soil characteristics of the area. Moreover, we put forward a method to identify L.chuanxiong's Daodi-zone 
https://doi.org/10.5194/soil-2021-37

Preprint. Discussion started: 17 May 2021

(c) Author(s) 2021. CC BY 4.0 License.

based on characteristic soil elements, which can also provide a practical basis for dividing other economic plants' growth environment.

Key words: Soil elements; Daodi-zone; geo-boundary; Ligusticum chuanxiong Hort.

\section{INTRODUCTION}

Soil is the environmental basis of plant growth, a variety of elements in the soil directly involved in plant growth and development, morphological construction and secondary metabolism, and then affect the accumulation of some compounds in plants, such as trace element boron (B) deficiency will lead to changes in cell wall structure(Guerriero et al., 2018;Matthes et al., 2020); B deficiency in tobacco leaves will induce the accumulation of soluble sugar and phenolic compounds (chlorogenic acid and coffee polyamine conjugates)(Camacho-Cristóbal et al., 2004). Besides, heavy metal element stress increases the accumulation of secondary metabolites by stimulating the plant to produce an immune response (Lajayer et al., 2017b). Since the soil properties are influenced by soil mass, topography, and geochemistry, it has a significant heterogeneity in geographical distribution, directly or indirectly affecting the absorption of plant elements and secondary metabolic synthesis (Guerriero et al., 2018;Bonari et al., 2019). At present, many studies have reported significant regional Heterogeneity in the accumulation of active ingredients in plants (Yang et al., 2018a; Li et al., 2020). In Sinopodophyllum hexandrum (Royle) T.S. Ying (Liu et al., 2015), conditions in Jingyuan, Ningxia Province, and Yongdeng, Gansu Province, are suitable for the production of podophyllotoxin and lignans, whereas conditions in Shangri-La, Yunnan Province, and Nyingchi, Tibet, are suitable for the production of quercetin and kaempferol. Simultaneously, Catechin and free amino acids in Green tea (Wen et al., 2020) are also affected by the cultivation location. Zhang et al. (Zhang et al., 2018) studied the secondary metabolites of Salvia miltiorrhiza Bunge, growing in different environmental factors and topographical conditions, magnesium $(\mathrm{Mg})$ and barium( $\mathrm{Ba})$ in the soil, negatively related to lead $(\mathrm{Pb})$, and that total nitrogen and potassium $(\mathrm{K})$ all contributed to the production of most phenolic acids.

In some areas, plants produced have better nutritional value or higher active substance content, which is generally considered the "high-quality" production area of the crop, referred to in this paper as 
https://doi.org/10.5194/soil-2021-37

Preprint. Discussion started: 17 May 2021

(c) Author(s) 2021. CC BY 4.0 License.

the "Daodi-zone". As Guo et al. (Guo et al., 2013) analyzing the influence of environmental factors on jaundice secondary metabolites found that the zone from Chifeng, Inner Mongolia to Taibai, Shaanxi is suitable for the accumulation of secondary metabolites of Scutellaria baicalensis. However, what is the scope of the Daodi-zone? Is there a natural boundary? What environmental factors determine the boundaries of the Daodi-zone? These questions have not been interpreted. In the past, the definition of Daodi-zone was judged based on human cultivation experience, and its scope was lacking in scientific experiments. Understanding the boundary of the Daodi-zone of plants is of great significance to the plant's rational introduction cultivation.

Although climate factors dominate regional heterogeneity on large spatial scales, spatial distribution differences in soil elements may significantly impact crop quality differences at medium and small spatial scales (Van der Putten et al., 2004;Santamaría et al., 2003). The geospatial variation of climate and soil factors is often inconsistent, resulting in different affect gradients (Macel et al., 2007). In the past, many studies have paid more attention on the variation of secondary metabolite content in large spatial scales or complex climate environments (Guo et al., 2013;Zhang et al., 2020), and there is an apparent lack of understanding of the heterogeneity of soil elements in the decision-setting of crop yields at medium and small spatial scales in the same climate environment. Therefore, this study mainly discusses the spatial distribution of soil elements and their characteristic effect on the boundary of L.chuanxiong's Daodi-zone.

Ligusticum chuanxiong Hort. is an important medicinal plant; its rhizomes have good efficacy in treating cardiovascular diseases, colds and arthritis (Chen et al., 2018). The Shiyang Town in Dujiangyan

80 City, Sichuan Province, has been recognized, at least from the Song Dynasty (960 A.D. to 1279 A.D.) in China, as producing the best medicinal value of L.chuanxiong, so is also known as L.chuanxiong's "Daodi-zone" (YIN et al., 2013), while L.chuanxiong outside Sichuan is produced as food. As a cultivated species, it is widely cultivated throughout China and cultivated in Japan and Korea. Hou (Hou, 2007) compared the quality of the same species L.chuanxiong in different cultivation region. He found significant differences in the content of active ingredients, indicating that the influence of the cultivation environment on the quality of L.chuanxiong is apparent(Ma et al., 2009). It is evident that there is a typical "regional effect" in the quality of L.chuanxiong. Therefore, L.chuanxiong can be used as a representative plant to study the relationship between the accumulation of secondary metabolites and Geospatial variation in medicinal plants at the small and medium scale. We choose the Shiyang Town in 
https://doi.org/10.5194/soil-2021-37

Preprint. Discussion started: 17 May 2021

(c) Author(s) 2021. CC BY 4.0 License.

Dujiangyan City (the center-zone) as the starting point, along the same latitude to the east interval multipoint sampling obtain soil samples. By testing soil element composition and content to identify the heterogeneity of the soil elements and chemical properties in Daodi-zone; This study provides a reference for the scientific definition of other medicinal plants' Daodi-zone by revealing the natural geographical extent of L.chuanxiong's Daodi-zone, and this method is of great value to the plant's rational introduction cultivation.

\section{MATERIALS AND METHODS}

\subsection{Sample plots}

The experiment was carried out in the fengdui village of Shiyang Town, Dujiangyan City $\left(30^{\circ} 50^{\prime} 10^{\prime} \mathrm{N}\right.$, $103^{\circ} 40^{\prime} 03^{\prime \prime E}$ ) and 280 kilometres eastwards at the same latitude (where the Tuojiang River separates E7 and E8, the Longquan Mountain chain separates E10 and E11; the Fujiang River separates E16 and E17; the Jialing River separates E23 and E24). Set Nine sample points in the center-zone and 28 sample points (one sample point per $10 \mathrm{~km}$ ) in the eastern extension zone (Table 1, Figure 1). Since L.chuanxiong is cultivated with rice alternately,, the experiment was conducted from August to September 2017, i.e. before the cultivation of L.chuanxiong after the rice harvest. A total of 37 bulk soils ( $5-20 \mathrm{~cm}$ depth) and

29 deep soils (150-180cm depth) were collected from rice paddies $(100 \mathrm{~m} \times 100 \mathrm{~m})$ of every sample points (3 biological replicates per sample). According to the HJ / T166-2004 guidelines (2004) to collect soil. To investigate the correlation between soil element changes and active ingredients. We planted L.chuanxiong in C0, E5 and E9 in May 2018, then collected samples of L.chuanxiong rhizomes, rhizosphere soil and bulk soil in mid-May 19.

Table 1 Information of the 37 sampling sites.

\begin{tabular}{llllllll}
\hline No. & Latitude & longitude & Altitude & No & Latitude & longitude & Altitude \\
\hline C0 & $30^{\circ} 50^{\prime} 10^{\prime \prime}$ & $103^{\circ} 40^{\prime} 0^{\prime \prime}$ & 592 & E11 & $30^{\circ} 50^{\prime} 42^{\prime \prime}$ & $104^{\circ} 49^{\prime} 21^{\prime \prime}$ & 471 \\
CS1 & $30^{\circ} 49^{\prime} 34^{\prime \prime}$ & $103^{\circ} 40^{\prime} 10^{\prime \prime}$ & 599 & E12 & $30^{\circ} 50^{\prime} 05^{\prime \prime}$ & $104^{\circ} 54^{\prime} 49^{\prime \prime}$ & 404 \\
CS2 & $30^{\circ} 47^{\prime} 36^{\prime \prime}$ & $103^{\circ} 40^{\prime} 08^{\prime \prime}$ & 600 & E13 & $30^{\circ} 50^{\prime} 38^{\prime \prime}$ & $105^{\circ} 01^{\prime} 51^{\prime \prime}$ & 387 \\
CE1 & $30^{\circ} 50^{\prime} 20^{\prime \prime}$ & $103^{\circ} 41^{\prime} 03^{\prime \prime}$ & 595 & E14 & $30^{\circ} 50^{\prime} 41^{\prime \prime}$ & $105^{\circ} 08^{\prime} 21^{\prime \prime}$ & 363 \\
CE2 & $30^{\circ} 50^{\prime} 10^{\prime \prime}$ & $103^{\circ} 43^{\prime} 12^{\prime \prime}$ & 589 & E15 & $30^{\circ} 50^{\prime} 54^{\prime \prime}$ & $105^{\circ} 14^{\prime} 22^{\prime \prime}$ & 357 \\
CW1 & $30^{\circ} 50^{\prime} 20^{\prime \prime}$ & $103^{\circ} 39^{\prime} 27^{\prime \prime}$ & 574 & E16 & $30^{\circ} 50^{\prime} 34^{\prime \prime}$ & $105^{\circ} 20^{\prime} 43^{\prime \prime}$ & 360
\end{tabular}


https://doi.org/10.5194/soil-2021-37

Preprint. Discussion started: 17 May 2021

(c) Author(s) 2021. CC BY 4.0 License.

\begin{tabular}{llllllll} 
CW2 & $30^{\circ} 49^{\prime} 55^{\prime \prime}$ & $103^{\circ} 36^{\prime} 50^{\prime \prime}$ & 585 & E17* & $30^{\circ} 49^{\prime} 47^{\prime \prime}$ & $105^{\circ} 26^{\prime} 40^{\prime \prime}$ & 351 \\
CN1 & $30^{\circ} 50^{\prime} 35^{\prime \prime}$ & $103^{\circ} 40^{\prime} 04^{\prime \prime}$ & 577 & E18* & $30^{\circ} 49^{\prime} 56^{\prime \prime}$ & $105^{\circ} 33^{\prime} 42^{\prime \prime}$ & 396 \\
CN2 & $30^{\circ} 52^{\prime} 59^{\prime \prime}$ & $103^{\circ} 40^{\prime} 15^{\prime \prime}$ & 645 & E19 & $30^{\circ} 49^{\prime} 30^{\prime \prime}$ & $105^{\circ} 39^{\prime} 12^{\prime \prime}$ & 577 \\
E1 & $30^{\circ} 50^{\prime} 30^{\prime \prime}$ & $103^{\circ} 46^{\prime} 02^{\prime \prime}$ & 563 & E20 & $30^{\circ} 50^{\prime} 26^{\prime \prime}$ & $105^{\circ} 45^{\prime} 47^{\prime \prime}$ & 535 \\
E2 & $30^{\circ} 50^{\prime} 16^{\prime \prime}$ & $103^{\circ} 52^{\prime} 51^{\prime \prime}$ & 502 & E21* & $30^{\circ} 50^{\prime} 32^{\prime \prime}$ & $105^{\circ} 52^{\prime} 06^{\prime \prime}$ & 475 \\
E3 & $30^{\circ} 50^{\prime} 16^{\prime \prime}$ & $103^{\circ} 58^{\prime} 46^{\prime \prime}$ & 482 & E22 & $30^{\circ} 50^{\prime} 28^{\prime \prime}$ & $105^{\circ} 58^{\prime} 32^{\prime \prime}$ & 458 \\
E4 & $30^{\circ} 50^{\prime} 22^{\prime \prime}$ & $104^{\circ} 05^{\prime} 46^{\prime \prime}$ & 465 & E23 & $30^{\circ} 51^{\prime} 51^{\prime \prime}$ & $106^{\circ} 04^{\prime} 32^{\prime \prime}$ & 457 \\
E5 & $30^{\circ} 50^{\prime} 52^{\prime \prime}$ & $104^{\circ} 11^{\prime} 58^{\prime \prime}$ & 440 & E24 & $30^{\circ} 50^{\prime} 13^{\prime \prime}$ & $106^{\circ} 10^{\prime} 55^{\prime \prime}$ & 442 \\
E6 & $30^{\circ} 49^{\prime} 20^{\prime \prime}$ & $104^{\circ} 17^{\prime} 41^{\prime \prime}$ & 435 & E25* & $30^{\circ} 49^{\prime} 22^{\prime \prime}$ & $106^{\circ} 17^{\prime} 02^{\prime \prime}$ & 422 \\
E7 & $30^{\circ} 50^{\prime} 31^{\prime \prime}$ & $104^{\circ} 23^{\prime} 54^{\prime \prime}$ & 440 & E26* & $30^{\circ} 49^{\prime} 36^{\prime \prime}$ & $106^{\circ} 23^{\prime} 22^{\prime \prime}$ & 818 \\
E8* & $30^{\circ} 50^{\prime} 52^{\prime \prime}$ & $104^{\circ} 30^{\prime} 33^{\prime \prime}$ & 453 & E27* & $30^{\circ} 50^{\prime} 18^{\prime \prime}$ & $106^{\circ} 29^{\prime} 54^{\prime \prime}$ & 439 \\
E9 & $30^{\circ} 50^{\prime} 37^{\prime \prime}$ & $104^{\circ} 36^{\prime} 39^{\prime \prime}$ & 424 & E28* & $30^{\circ} 50^{\prime} 22^{\prime \prime}$ & $106^{\circ} 35^{\prime} 32^{\prime \prime}$ & 450 \\
E10 & $30^{\circ} 50^{\prime} 09^{\prime \prime}$ & $104^{\circ} 12^{\prime} 52^{\prime \prime}$ & 418 & & & & \\
\hline
\end{tabular}

The "*" marker is that deep soil sample has not been collected.

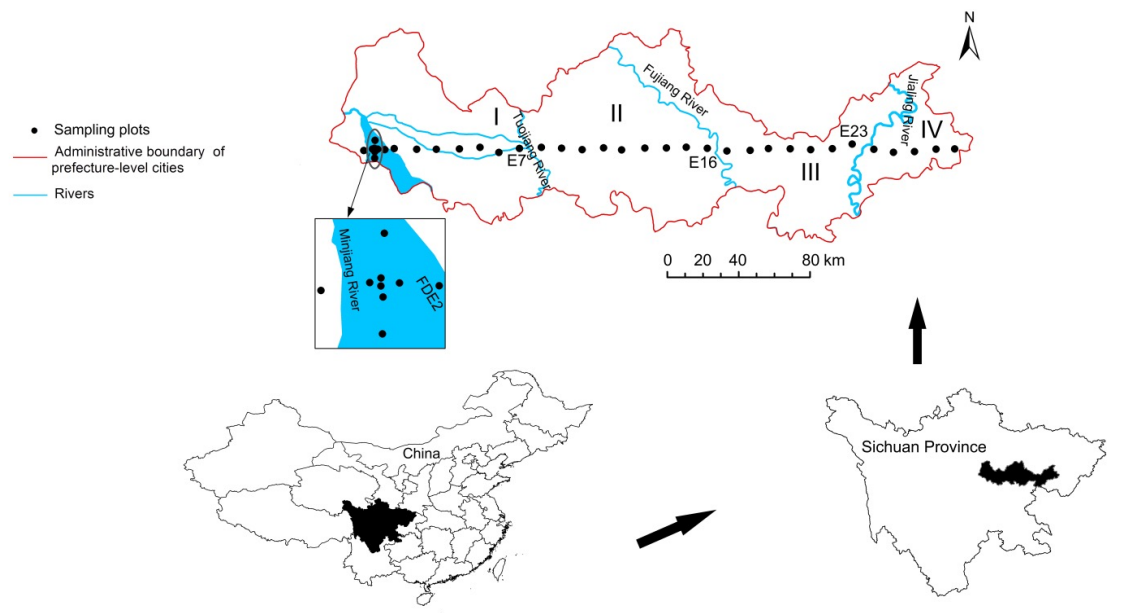

Figure 1 Sample plot. Locations of 37 sample points for this study. Maps generated by ArcMap.

\subsection{Sample processing}

115 Ground natural air-dried soil samples into three sizes $(2 \mathrm{~mm}, 0.15 \mathrm{~mm}$ and $0.074 \mathrm{~mm})$ to determine soil $\mathrm{pH}$, organic matter and inorganic elements. Measuring $\mathrm{pH}$ in the ratio of 1:2.5 between soil and water with the Spectrum 2105 SoilStik pH meter (Spectrum Technologies, Inc., Aurora, IL, USA). Organic 
https://doi.org/10.5194/soil-2021-37

Preprint. Discussion started: 17 May 2021

(c) Author(s) 2021. CC BY 4.0 License.

matter content determination uses $\mathrm{K}_{2} \mathrm{Cr}_{2} \mathrm{O}_{7}-\mathrm{H}_{2} \mathrm{SO}_{4}$ to determine organic matter content (Bao, 2000). Then, soil powder was prepared as a stable disc pellet to detect the inorganic element concentrations with a wavelength dispersive X-ray fluorescence (XRF) spectrometer S8 tiger (Fang et al., 2020).

For plant samples, rhizomes were washed, dried and grounded $(0.25 \mathrm{~mm})$. Each powder was acidified by the addition of $\mathrm{HNO} 3$ and made up to $25 \mathrm{~mL}$ with deionized water for the determination of element concentrations using a Nex10N 350x ICP-MS (Perkin Elmer, America), adding In115 as an internal element standard. Additionally, the contents analysis of senkyunolide A, senkyunolide I, senkyunolide H, Ferulic Acid, ligustilide and coniferyl ferulate was achieved using analytical highperformance liquid chromatography (HPLC) with an Agilent 1200 series HPLC system. According to the fourth edition of the Chinese Pharmacopoeia, we detect the moisture content, total ash, insoluble acid ash, and leachate in plant samples (Wang, 2015).

\subsection{Data analysis}

130 All statistical analysis is performed in R 4.0.3(Team, 2013). Using the Shapiro-Wilk test to check the normal distribution of the data, using a one-way analysis of variance or Kruskal-Wallis test to assess the difference between the groups of samples, the Duncan test for two post-mortem tests, the p-value was corrected using Bonferroni. The multi-statistical analysis uses the Vegan 2.5-7 package (Oksanen et al., 2013). After converting inorganic element data into European distances, hierarchical clustering is performed using unmeasured group arithmetic averages (UPGMA). PCA analysis and ANOSIM similarity testing based on clustering results. Using the simil function in the proxy package (Meyer and Buchta, 2020) to calculate the Eastern extension zone sample's similarity to elements in the center-zone, then linearly fit it with soil organic matter, $\mathrm{pH}$, and altitude, and test its significance with a permutation test. Use the corrplot package to calculate the Pearson correlation coefficient of the active ingredients in the roots of L.chuanxiong and the element content and plot the correlation(Wei et al., 2017). The formula for calculating the bioconcentration factors:

$$
\mathrm{BCF}=\frac{\text { CRhizome }}{\text { CSoil }} * 100 \%
$$

Where, in Eq. (1), BCF is an indicator of an element's tendency to accumulate in the organism. CRhizome is the Concentration of the element in the rhizome, CSoil is the Concentration of the element in rhizosphere soil.

The formula for calculating the background change rate of soil chemical elements (Cheng et al., 2014) is 
https://doi.org/10.5194/soil-2021-37

Preprint. Discussion started: 17 May 2021

(c) Author(s) 2021. CC BY 4.0 License.

Where, in Eq. (2), $\triangle \mathrm{RCi}$ is the rate of change of the natural background of element i, GBLi is the geochemical reference value of the $\mathrm{i}$ element, and GBGi is the geochemical background value of $\mathrm{i}$ element. When $|\Delta \mathrm{RCi}| \geq 100$, it indicates a significant increase or decrease in the i element, when $50 \leq|\Delta \mathrm{RCi}| \leq 100$ indicates a significant increase or decrease in the i element, and when $0 \leq|\Delta \mathrm{RCi}| \leq 50$ indicates an increase or decrease in the i element.

\section{RESULTS}

\subsection{Heterogeneity of Daodi and eastern extension zone}

To compare soil heterogeneity in the center-zone and eastern extension zone, we sampled soil in the zone mentioned above at intervals of $10 \mathrm{~km}$ and analyzed soil elements' differences and physical-chemical characteristics in the study area.

\subsubsection{Cluster analysis of soil element}

To clarify the similarity of soil elements between the Daodi-zone and the eastern extension zone, we normalized the data of soil elements and clustered them using arithmetic average non-weight grouping, with all soil samples clustered into three groups, Cluster1, Cluster2, Cluster3 (Figure 2, Table 2). Among them, samples from all Daodi-zone are called center and are included in Cluster1. The E11-E14, E16E19, which are geographically close to the center group, are clustered as Cluster 2; The E20, E21, E23 and E28 are far away from the center group as Cluster 3. The results show that the element similarity of most sample points is related to geographical location (Table 2). Still, a few sample points (E15, E22 and E24-E27) are far away from the center-zone but have similar element characteristics to the center group. Based on three clustered samples for PCA analysis, and ANOSIM similarity test results show significant differences between groups (Figure 3, $\mathrm{P}<0.05$ ).

Among them, center-zone's $\mathrm{pH}$ is the lowest, 6.80. As the distance farther and farther from the center-zone, the $\mathrm{pH}$ value shows an upward trend. The center group also maintained the same organic matter content as Cluster 1 and Cluster2, but Cluster 3 had a higher OM of $38603.75 \mathrm{mg} / \mathrm{Mg}$. In addition, the center group had only $\mathrm{Cl}, \mathrm{Br}, \mathrm{La}$, and $\mathrm{Th}$ with lower average concentration levels than the other group samples. The center group is rich in P $(1103.28 \mathrm{mg} / \mathrm{Kg}), \mathrm{K}(23956.79 \mathrm{mg} / \mathrm{Kg}), \mathrm{Mg}(12106.17 \mathrm{mg} / \mathrm{Kg})$ 
https://doi.org/10.5194/soil-2021-37

Preprint. Discussion started: 17 May 2021

(c) Author(s) 2021. CC BY 4.0 License.

and $\mathrm{Fe}(38904.94 \mathrm{mg} / \mathrm{Kg}$ ) compared to the elemental background values of Dujiangyan City (Tang et al., 2005). $\mathrm{Mn}(342.42 \mathrm{mg} / \mathrm{Kg})$ and $\mathrm{Ca}(9623.46 \mathrm{mg} / \mathrm{Kg})$ are slightly missing from the required trace elements in the center group. Heavy metal elements $\mathrm{Cu}, \mathrm{Cr}, \mathrm{Pb}, \mathrm{Ni}$ and $\mathrm{Zn}$ are all higher than the background value, 1.28 to 1.58 times the background value, and As is lower than the background value and 0.46 times the background value. These heavy metal elements meet the national standard requirements (GB156182018): $\mathrm{Cr} \leq 300$ mg.kg-1, As $\leq 25$ mg.kg-1, $\mathrm{Ni} \leq 100$ mg.kg-1, $\mathrm{Cu} \leq 100$ mg.kg-1, $\mathrm{Zn} \leq 250$ mg.kg-1, $\mathrm{Pb} \leq 140$ mg.kg-1. By comparing the characteristics of soil elements, we found that the center-zone is the characteristics of the alluvial soil (Huang and Jiang, 2010). Most of these element concentrations are higher than the background values of Chinese soil elements (layer A), mainly due to human intervention and the use of basic magma rock as their material source (Chen et al., 1991;He et al., 2006;Yang et al., 2013). In addition, $\mathrm{Ca}$ in slightly acidic sandy soils can easily move downwards due to the humid and long-term flooded environment of the soil in the rice paddies. During the growth and development of rice, Mn (II.) and As (III.) (absorbed by iron oxide at the roots of rice) are absorbed (Chakravarty et al., 2002; Singh et al., 2011;Ma et al., 2018), resulting in concentrations of Ca, Mn and As being lower than the background values.

The concentration levels of a small number of elements in Clusterl (excluding the center group sample) were higher than those in the center group, but the average increase was no more than $40.33 \%$. In addition, the average concentration level of most elements in Clusterl is higher than that of the Cluster 2 (up to 29.29\%) and Cluster 3 (up to $43.40 \%$ ). In the Cluster 2 and Cluster 3 groups, most elements were at similar concentration, but $\mathrm{Ca}, \mathrm{S}$ and $\mathrm{Cl}$ in Cluster2 were higher, while $\mathrm{Mg}, \mathrm{Mn}$ and $\mathrm{As}$ in Cluster3 were higher. It is worth noting that the concentration levels of $\mathrm{Na}$ in these two regions are about half the background value. 
https://doi.org/10.5194/soil-2021-37

Preprint. Discussion started: 17 May 2021

(c) Author(s) 2021. CC BY 4.0 License.

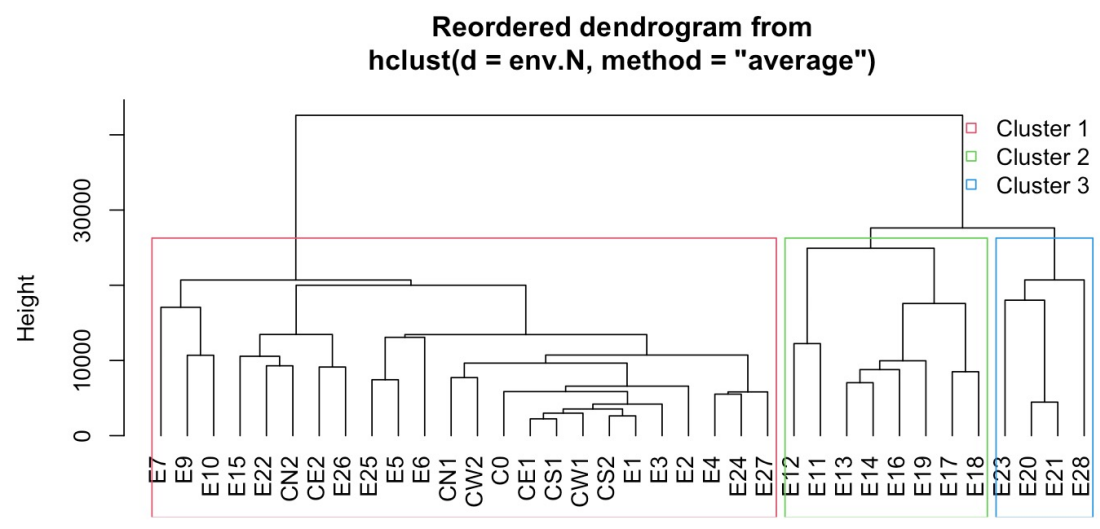

36 sites

3 clusters

Figure 2 Clustering dendrogram. Based on the Euclidean distance metric, the inorganic elements of various points are hierarchically clustered using the unweighted pair group method with arithmetic mean method. Bulk soil samples include $9(\mathrm{C} 0-\mathrm{CN} 2)$ in center-zone and 28 in Eastern Extension zone, for a total of 37 samples. cluster groups 3, Cluster1, Cluster2 and Cluster3, of which Cluster1 contains Center group samples (C0, CS1, CS2, CE1, CE2, CW1, CW2, CN1, CN2).

Table 2 The elemental content of the bulk soil

\begin{tabular}{llllll}
\hline Element & Center & Cluster1 & Cluster2 & Cluster3 & Bac.lev \\
\hline $\mathrm{Na}$ & $10459.26 \pm 1155.62$ & $7652.59 \pm 1688.75$ & $5411.11 \pm 541.86$ & $4983.33 \pm 960.47$ & 10200 \\
$\mathrm{Mg}$ & $12106.17 \pm 1057.35$ & $11543.70 \pm 2376.04$ & $12656.94 \pm 2000.55$ & $15572.22 \pm 1811.32$ & 7800 \\
$\mathrm{Al}$ & $86171.60 \pm 4520.84$ & $81897.78 \pm 4712.05$ & $72916.67 \pm 2196.53$ & $78727.78 \pm 2470.44$ & 66200 \\
$\mathrm{Si}$ & $282930.9 \pm 2778.61$ & $284609.6 \pm 6488.69$ & $266629.2 \pm 7231.95$ & $265861.1 \pm 5281.43$ & -- \\
$\mathrm{P}$ & $1103.28 \pm 202.86$ & $891.73 \pm 327.60$ & $833.25 \pm 94.06$ & $784.06 \pm 51.38$ & - \\
$\mathrm{S}$ & $140.53 \pm 34.11$ & $173.67 \pm 94.88$ & $268.21 \pm 77.21$ & $98.31 \pm 85.35$ & - \\
$\mathrm{Cl}$ & $60.78 \pm 6.71$ & $76.56 \pm 16.88$ & $103.90 \pm 25.72$ & $79.72 \pm 5.00$ & - \\
$\mathrm{K}$ & $23956.79 \pm 1667.60$ & $22264.44 \pm 3495.61$ & $20802.78 \pm 1488.42$ & $24316.67 \pm 1314.83$ & 18600 \\
$\mathrm{Ca}$ & $9623.46 \pm 5400.28$ & $11385.19 \pm 6357.36$ & $50059.72 \pm 8362.27$ & $33002.78 \pm 9059.39$ & 15400 \\
$\mathrm{Fe}$ & $38904.94 \pm 1326.80$ & $39697.04 \pm 4241.01$ & $35011.11 \pm 2920.43$ & $43041.67 \pm 3986.56$ & 29400 \\
$\mathrm{Sc}$ & $14.60 \pm 0.56$ & $13.74 \pm 1.56$ & $12.68 \pm 0.99$ & $14.05 \pm 1.36$ & - \\
$\mathrm{Ti}$ & $4532.20 \pm 91.48$ & $4523.73 \pm 238.73$ & $4039.35 \pm 215.77$ & $4474.05 \pm 64.90$ & 3800 \\
$\mathrm{~V}$ & $121.44 \pm 7.49$ & $109.03 \pm 16.44$ & $91.85 \pm 8.37$ & $110.97 \pm 9.32$ & 82.4
\end{tabular}




\begin{tabular}{|c|c|c|c|c|c|}
\hline $\mathrm{Cr}$ & $88.61 \pm 5.69$ & $84.18 \pm 10.57$ & $73.06 \pm 2.21$ & $85.68 \pm 9.12$ & 61 \\
\hline $\mathrm{Mn}$ & $342.42 \pm 60.37$ & $531.39 \pm 196.99$ & $685.47 \pm 125.09$ & $718.12 \pm 107.77$ & 583 \\
\hline $\mathrm{Co}$ & $29.26 \pm 5.51$ & $25.62 \pm 7.63$ & $23.63 \pm 5.58$ & $20.23 \pm 1.52$ & 12.7 \\
\hline $\mathrm{Ni}$ & $38.38 \pm 1.43$ & $38.16 \pm 4.23$ & $38.27 \pm 1.90$ & $46.49 \pm 7.06$ & 26.9 \\
\hline $\mathrm{Cu}$ & $35.78 \pm 3.38$ & $32.43 \pm 6.91$ & $25.30 \pm 2.38$ & $32.27 \pm 5.35$ & 22.6 \\
\hline $\mathrm{Zn}$ & $94.93 \pm 16.34$ & $90.72 \pm 25.90$ & $75.31 \pm 16.40$ & $103.03 \pm 10.74$ & 74.2 \\
\hline $\mathrm{Ga}$ & $20.36 \pm 1.44$ & $19.68 \pm 1.76$ & $18.12 \pm 0.95$ & $20.56 \pm 0.91$ & 17.5 \\
\hline As & $5.13 \pm 2.37$ & $8.59 \pm 3.14$ & $8.64 \pm 2.79$ & $12.56 \pm 2.46$ & 11.2 \\
\hline $\mathrm{Br}$ & $1.34 \pm 0.18$ & $1.70 \pm 0.45$ & $2.74 \pm 0.80$ & $2.44 \pm 0.18$ & -- \\
\hline $\mathrm{Rb}$ & $122.03 \pm 13.70$ & $120.66 \pm 14.43$ & $112.65 \pm 9.93$ & $129.69 \pm 4.32$ & 111 \\
\hline $\mathrm{Sr}$ & $174.94 \pm 27.75$ & $153.39 \pm 21.42$ & $166.52 \pm 33.28$ & $154.82 \pm 31.86$ & 167 \\
\hline $\mathrm{Y}$ & $29.64 \pm 0.38$ & $29.11 \pm 1.74$ & $26.89 \pm 1.42$ & $27.53 \pm 0.63$ & 22.9 \\
\hline $\mathrm{Zr}$ & $232.37 \pm 11.43$ & $235.65 \pm 23.10$ & $212.59 \pm 23.85$ & $197.91 \pm 16.77$ & 256 \\
\hline $\mathrm{Ba}$ & $615.20 \pm 43.29$ & $569.89 \pm 63.79$ & $580.19 \pm 52.89$ & $528.50 \pm 43.12$ & 469 \\
\hline $\mathrm{La}$ & $35.95 \pm 2.61$ & $39.63 \pm 4.23$ & $41.44 \pm 2.01$ & $44.77 \pm 2.23$ & -- \\
\hline Hf & $6.60 \pm 0.32$ & $6.58 \pm 0.46$ & $6.10 \pm 0.50$ & $5.79 \pm 0.45$ & -- \\
\hline $\mathrm{Pb}$ & $34.53 \pm 5.01$ & $30.90 \pm 4.25$ & $25.71 \pm 1.68$ & $29.37 \pm 1.63$ & 26 \\
\hline $\mathrm{Ce}$ & $73.50 \pm 3.09$ & $74.88 \pm 4.52$ & $71.10 \pm 2.78$ & $73.31 \pm 2.26$ & 68.4 \\
\hline Th & $12.58 \pm 0.60$ & $12.66 \pm 1.12$ & $14.48 \pm 1.53$ & $15.49 \pm 0.78$ & -- \\
\hline $\mathrm{Cd}$ & $0.39 \pm 0.04$ & $0.41 \pm 0.08$ & $0.45 \pm 0.10$ & $0.39 \pm 0.09$ & -- \\
\hline $\mathrm{TN}$ & $1421.82 \pm 260.65$ & $1385.24 \pm 213.84$ & $1386.53 \pm 284.81$ & $1862.40 \pm 256.81$ & -- \\
\hline Altitude & $595.11 \pm 20.77$ & $473.67 \pm 105.41$ & $413.62 \pm 76.02$ & $479.25 \pm 38.63$ & -- \\
\hline $\mathrm{pH}$ & $6.80 \pm 0.76$ & $7.38 \pm 0.71$ & $8.10 \pm 0.13$ & $7.91 \pm 0.08$ & -- \\
\hline $\mathrm{OM}$ & $28535.00 \pm 3626.18$ & $26656.11 \pm 5239.29$ & $28036.25 \pm 7947.14$ & $38603.75 \pm 5311.97$ & -- \\
\hline
\end{tabular}

Samples of Center, Cluster1, Cluster2, and Cluster 3 are shown in figure 2. Inorganic element content is

205 in $\mathrm{mg} / \mathrm{kg}$. The value after " \pm " is the standard deviation, and all data is kept in two places. Bac.lev is the background value of the reference chemical element in the Dujiangyan region. TN is total nitrogen and $\mathrm{OM}$ is organic. 


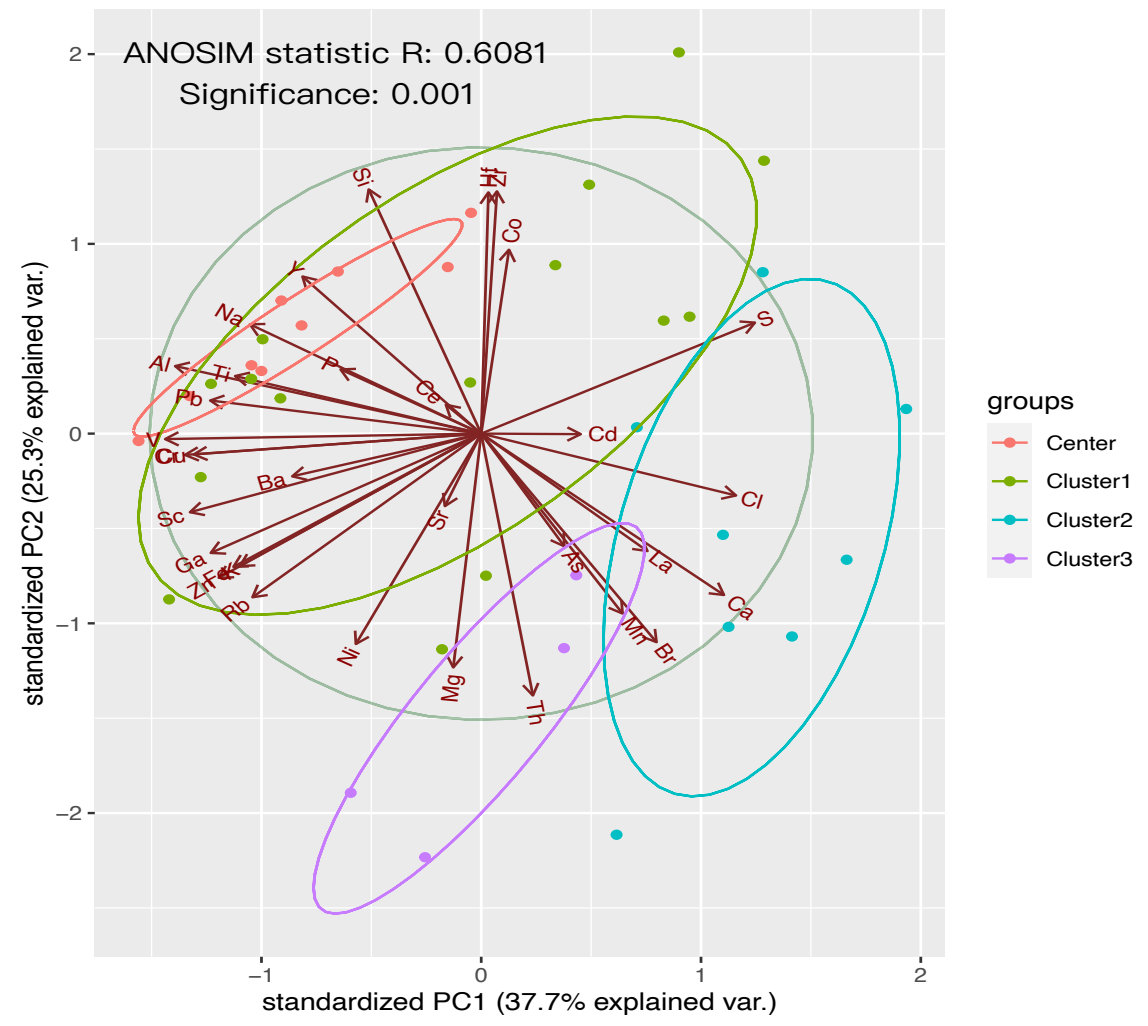

Figure 3 PCA plot. PCA analysis of inorganic element data in rhizome samples based on standardized distance matrices. Samples of Center, Cluster1, Cluster2, and Cluster 3 are shown in Figure 2. The ANOSIM similarity test showed significant differences among groups at $95 \%$ confidence levels $(\mathrm{P}<0.05)$.

\subsubsection{The dissimilarity of nutritional content ratio in soil}

We measured the ratios of $\mathrm{Fe} / \mathrm{Mn}, \mathrm{Na} / \mathrm{K}, \mathrm{Zn} / \mathrm{Cu}, \mathrm{Ca} / \mathrm{P}$, and $\mathrm{K} / \mathrm{Mg}$ in the soil to determine soil nutrition's heterogeneity in different regions (Fageria, 2001;Khan et al., 2009;Andrade et al., 2010; Senbayram et al., 2016;Bornø et al., 2018). The Kruskal-Wallis test showed significant differences between groups (Table 3), and the Duncan test showed no significant differences between the center-zone and the other nutrient ratios of Cluster1, except for the significant differences of $\mathrm{Ca} / \mathrm{P}$ ratios across all groups. There was no significant difference in the $\mathrm{Fe} / \mathrm{Mn}, \mathrm{Zn} / \mathrm{Cu}$ between Cluster1 and Cluster2, and no significant difference in the $\mathrm{Fe} / \mathrm{Mn}, \mathrm{Na} / \mathrm{K}, \mathrm{Zn} / \mathrm{Cu}$, and $\mathrm{K} / \mathrm{Mg}$ between Cluster2 and Cluster 3. Among them, the $\mathrm{Fe} / \mathrm{Mn}, \mathrm{Na} / \mathrm{K}$ and $\mathrm{K} / \mathrm{Mg}$ of the Center group had the highest ratio compared to the other three expansion 
https://doi.org/10.5194/soil-2021-37

Preprint. Discussion started: 17 May 2021

(c) Author(s) 2021. CC BY 4.0 License.

zone samples, increasing by an average of $44.1 \%, 38.6 \%$ and $13.3 \%$, respectively, while the $\mathrm{Ca} / \mathrm{P}$ and $\mathrm{Zn} / \mathrm{Cu}$ ratios were the lowest, with an average decrease of $369 \%$ and $13.3 \%$, respectively.

Table 3 The ratio of nutritional element

\begin{tabular}{ccccc}
\hline & CENTER & CLUSTER1 & CLUSTER2 & CLUSTER3 \\
\hline $\mathbf{F E} / \mathbf{M N}$ & $116.82 \pm 20.88 \mathrm{a}$ & $82.52 \pm 26.92$ & $52.40 \pm 9.13 \mathrm{a}$ & $61.10 \pm 11.87 \mathrm{a}$ \\
$\mathbf{N A} / \mathbf{K}$ & $0.44 \pm 0.07 \mathrm{a}$ & $0.34 \pm 0.05 \mathrm{~b}$ & $0.26 \pm 0.03 \mathrm{ab}$ & $0.21 \pm 0.05 \mathrm{ab}$ \\
$\mathbf{Z N} / \mathbf{C U}$ & $2.64 \pm 0.32 \mathrm{a}$ & $2.80 \pm 0.52$ & $2.95 \pm 0.44$ & $3.22 \pm 0.21 \mathrm{a}$ \\
$\mathbf{C A} / \mathbf{P}^{*}$ & $8.38 \pm 3.10$ & $14.52 \pm 9.15$ & $61.24 \pm 0.44$ & $42.14 \pm 10.92$ \\
$\mathbf{K} / \mathbf{M G}$ & $2.00 \pm 0.24 \mathrm{a}$ & $1.96 \pm 0.24 \mathrm{~b}$ & $1.67 \pm 0.18 \mathrm{ab}$ & $1.57 \pm 0.11 \mathrm{ab}$ \\
\hline
\end{tabular}

The table shows the ratio of the nutritional element, and the sample composition of Center, Cluster1, 2, and 3 are shown in figure 2. Using the Kruskal-Wallis test and the Duncan test, detect the difference between groups; the confidence level was $95 \%$. The lowercase letter a is a significant difference between the Center group sample and the rest of the sample, the lowercase letter $b$ is a significant difference between Cluster 1 and Cluster 2 or Cluster 3, and “*” means there is a significant difference among all groups in $\mathrm{Ca} / \mathrm{P}(\mathrm{P}<0.05)$.

\subsubsection{The similarity analysis of soil elements and linear regression analysis}

235 Calculate the element similarity between the Daodi-zone and the samples in the eastern extension zone. We found that the elemental similarity coefficient of the sample decreased at the beginning the further away from the Daodi-zone, reaching the lowest point at E13 (0.53), and then gradually recovered, reaching the highest value at E27 (0.78) (Table 4). The content of altitude, $\mathrm{pH}$ and soil organic matter was linearly fitted with similar coefficients, and the permutation test showed that the similar coefficients of soil element spectrum were positive correlation with altitude and negatively correlated with $\mathrm{pH}$ and OM (Figure 4, $\mathrm{P}<0.05$ ).

Table 4 The similarity coefficient of the element 
https://doi.org/10.5194/soil-2021-37

Preprint. Discussion started: 17 May 2021

(c) Author(s) 2021. CC BY 4.0 License.

\begin{tabular}{llllll}
\hline sample & S.I & sample & S.I & sample & S.I \\
\hline E1 & 0.92 & E11 & 0.72 & E20 & 0.72 \\
E2 & 0.91 & E12 & 0.68 & E21 & 0.75 \\
E3 & 0.89 & E13 & 0.56 & E22 & 0.74 \\
E4 & 0.87 & E14 & 0.67 & E23 & 0.64 \\
E5 & 0.83 & E15 & 0.73 & E24 & 0.73 \\
E6 & 0.77 & E16 & 0.61 & E25 & 0.75 \\
E7 & 0.67 & E17 & 0.63 & E26 & 0.75 \\
E9 & 0.68 & E18 & 0.65 & E27 & 0.80 \\
E10 & 0.63 & E19 & 0.66 & E28 & 0.66 \\
\hline
\end{tabular}

Based on the "simil" function in the proxy package, we calculate the similarity coefficient between the

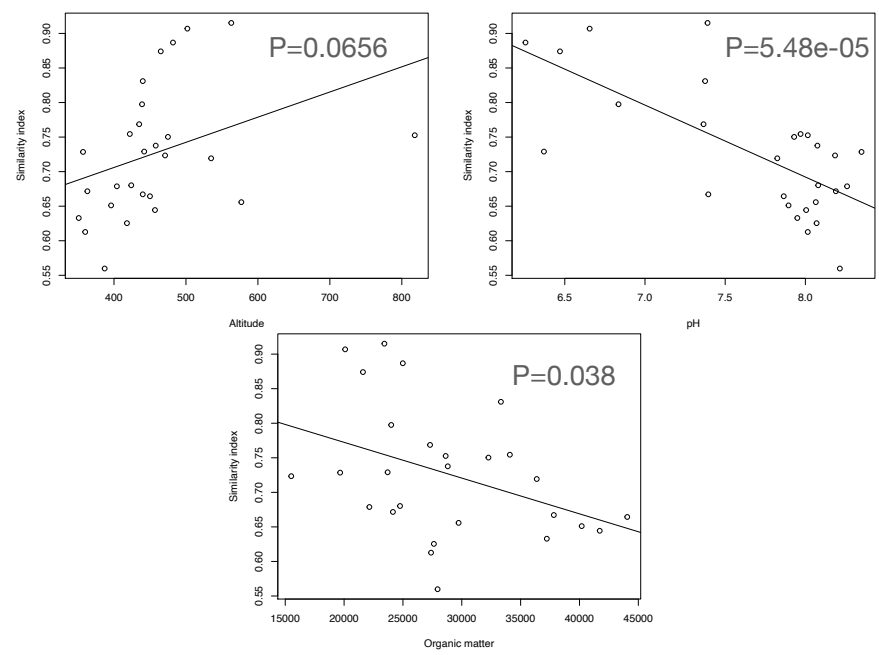

Figure 4 Linear regression. Analyzing the linear regression between elemental similar coefficients and altitude, $\mathrm{pH}$, and organic matter at a confidence level of $95 \%(\mathrm{P}<0.05)$. 
https://doi.org/10.5194/soil-2021-37

Preprint. Discussion started: 17 May 2021

(c) Author(s) 2021. CC BY 4.0 License.

$250 \quad 3.2$ Soil elements shape the characteristics of the absorption of elements of L.chuanxiong and the accumulation of active ingredients

\subsubsection{Analysis of the active ingredients and elements}

To verify the effect of soil element changes on active ingredients, we chose to conduct field cultivation experiments at E5 and E9 points, which belong to different cluster trees in Cluster1, using C0 sample points as a control group. Then sample rhizome, rhizosphere soil and bulk soil in mid-May 19. We measured the content of ingredients and elements in the rhizome (Table 5). The one-way analysis of variance between groups showed significant differences in the content of ligustilide and moisture. Then Duncan's test shows significant differences in the ligustilide and moisture between the $\mathrm{C} 0$ and $\mathrm{E} 9$ sample points $(\mathrm{P}<0.05)$, with no significant difference with E5. Besides, correlation analysis of the active ingredients and elements in the rhizome showed a significant negative correlation between $\mathrm{Mn}$ and Coniferyl Ferulate and Ligustilide, a significant positive correlation with Ferulic Acid, and a significant positive correlation between Se and Senkyunolide I, Senkyunolide H and Ligustilide, and a significant positive correlation between $\mathrm{Sr}$ and Ligustilide (Figure 5, $\mathrm{P}<0.05$ ).

Table 5 The content of ingredients and elements in the rhizome

\begin{tabular}{llll}
\hline & C0 & E5 & E9 \\
\hline Content & & & \\
Senkyunolide A & $0.93 \pm 0.20$ & $0.91 \pm 0.28$ & $0.81 \pm 0.16$ \\
Senkyunolide I & $0.013 \pm 0.004$ & $0.016 \pm 0.006$ & $0.011 \pm 0.003$ \\
Senkyunolide H & $0.004 \pm 0.001$ & $0.004 \pm 0.002$ & $0.003 \pm 0.001$ \\
Ferulic Acid & $0.018 \pm 0.003$ & $0.019 \pm 0.005$ & $0.10 \pm 0.14$ \\
Coniferyl ferulate & $0.45 \pm 0.088$ & $0.48 \pm 0.14$ & $0.24 \pm 0.20$ \\
Ligustilide & $2.26 \pm 0.20 \mathrm{a}$ & $2.19 \pm 0.41$ & $1.75 \pm 0.03 \mathrm{a}$ \\
Alcohol soluble extract & $29.77 \pm 2.14$ & $30.60 \pm 2.56$ & $29.10 \pm 0.90$ \\
Total ash & $4.16 \pm 0.40$ & $3.67 \pm 0.27$ & $4.28 \pm 0.42$ \\
Acid insoluble ash & $0.55 \pm 0.15$ & $0.37 \pm 0.15$ & $0.35 \pm 0.064$ \\
moisture & $9.53 \pm 0.88 \mathrm{a}$ & $8.32 \pm 0.38$ & $8.03 \pm 0.96 \mathrm{a}$ \\
Element & & &
\end{tabular}


https://doi.org/10.5194/soil-2021-37

Preprint. Discussion started: 17 May 2021

(c) Author(s) 2021. CC BY 4.0 License.

Zn

B

$\mathrm{Ca}$

K

$\mathrm{Na}$

$\mathrm{Mg}$

P

$\mathrm{AL}$

$\mathrm{Ti}$

V

$\mathrm{Cr}$

Mn

$\mathrm{Fe}$

Co

$\mathrm{Ni}$

$\mathrm{Cu}$

$\mathrm{Ga}$

As

$\mathrm{Se}$

$\mathrm{Rb}$

$\mathrm{Sr}$

Y

$\mathrm{Zr}$

Mo

Cd

$\mathrm{Ba}$

La

$\mathrm{Ce}$

Nd
$28.24 \pm 7.44$

$18.008 \pm 1.87$

$3009.31 \pm 597.93$

$7703.98 \pm 885.49$

$1425.50 \pm 370.70$

$2266.99 \pm 287.51$

$4267.74 \pm 825.86$

$135.35 \pm 86.36$

$3.95 \pm 1.74$

$0.31 \pm 0.20$

$0.31 \pm 0.16$

$25.67 \pm 5.06$

$111.00 \pm 48.96$

$2.34 \pm 1.20$

$2.05 \pm 0.74$

$8.84 \pm 1.44$

$1.11 \pm 0.44$

$0.15 \pm 0.043$

$0.044 \pm 0.018$

$7.48 \pm 3.00$

$21.19 \pm 2.97$

$0.072 \pm 0.036$

$0.084 \pm 0.03$

$0.15 \pm 0.08$

$0.32 \pm 0.21$

$12.63 \pm 5.09$

$0.11 \pm 0.055$

$0.15 \pm 0.089$

$0.068 \pm 0.041$
$29.75 \pm 5.90$

$15.81 \pm 1.26$

$1920.21 \pm 203.68$

$6665.97 \pm 456.83$

$1470.54 \pm 198.23$

$2096.22 \pm 184.49$

$4554.83 \pm 400.53$

$26.00 \pm 8.40$

$1.64 \pm 0.36$

$0.062 \pm 0.016$

$0.14 \pm 0.086$

$25.64 \pm 5.16$

$49.98 \pm 7.74$

$4.05 \pm 5.06$

$1.71 \pm 0.46$

$9.76 \pm 3.02$

$0.75 \pm 0.13$

$0.064 \pm 0.017$

$0.055 \pm 0.032$

$9.73 \pm 1.91$

$14.10 \pm 1.71$

$0.014 \pm 0.003$

$0.024 \pm 0.004$

$0.12 \pm 0.052$

$0.18 \pm 0.10$

$7.86 \pm 1.36$

$0.024 \pm 0.006$

$0.035 \pm 0.01$

$0.015 \pm 0.004$
$28.93 \pm 2.19$

$14.03 \pm 0.59$

$2038.10 \pm 253.43$

$9302.22 \pm 1572.60$

$559.26 \pm 348.79$

$1944.53 \pm 138.37$

$4793.27 \pm 183.55$

$25.21 \pm 0.53$

$1.65 \pm 0.17$

$0.062 \pm 0.012$

$0.083 \pm 0.011$

$37.75 \pm 9.17$

$39.76 \pm 1.94$

$2.64 \pm 1.08$

$1.74 \pm 0.50$

$12.10 \pm 0.88$

$0.64 \pm 0.27$

$0.051 \pm 0.012$

$0.012 \pm 0.011$

$3.62 \pm 1.72$

$9.26 \pm 0.24$

$0.026 \pm 0.012$

$0.026 \pm 0.006$

$0.076 \pm 0.021$

$0.11 \pm 0.025$

$7.38 \pm 3.21$

$0.033 \pm 0.019$

$0.049 \pm 0.024$

$0.026 \pm 0.014$ 
https://doi.org/10.5194/soil-2021-37

Preprint. Discussion started: 17 May 2021

(c) Author(s) 2021. CC BY 4.0 License.

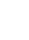

$\mathrm{Pb}$

$0.51 \pm 0.21$

$0.28 \pm 0.13$

$0.27 \pm 0.13$

The active ingredients and regular component units are \%, and the inorganic element content units are $\mathrm{mg} / \mathrm{kg}$. The value after " \pm " is the standard deviation and keep all data in two places. The lowercase letter "a" indicates a significant difference in the belief level of an ingredient between groups at $95 \%$. The Pvalue is corrected using Bonferroni $(\mathrm{P}<0.05)$.

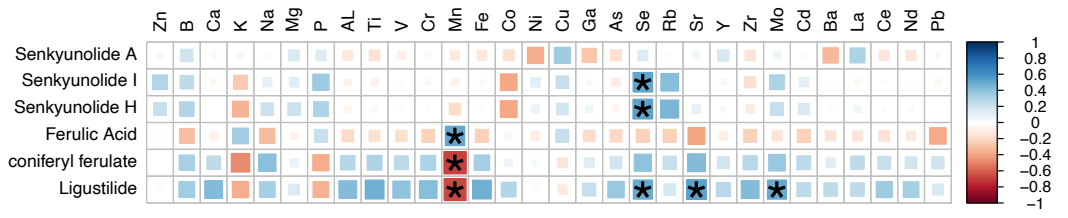

Figure 5 Correlation analysis. Pearson correlation analysis of active ingredients and elements in the rhizome, $" * "$ indicates a significant difference at a $95 \%$ confidence level $(\mathrm{P}<0.05)$.

\subsubsection{Analysis of the characteristics of soil and rhizome absorption element}

275 PCA analysis of the composition and content data (Table 6) of bulk soil, rhizosphere soil and rhizome at each sample points, and the ANOSIM test shows significant differences among groups (Figure 6, $\mathrm{P}<0.05$ ). Moreover, as the distance farther and farther from $\mathrm{C} 0, \mathrm{pH}$ in the rhizosphere and bulk soil samples shows an upward trend, while OM shows a downward trend.

To understand the characteristics of the absorption of different elements by the L.chuanxiong's rhizome at three sample points, we calculated the bioconcentration factors $(\mathrm{BCF})$ of elements in the rhizome (Table 6). The highest BCF (2.24-7.4) of $\mathrm{P}$ in the rhizome was found in all three sets of samples, with a BCF average of 0.08-0.099 for other elements. It is worth noting that there is no obvious correlation between the content of $\mathrm{Zn}$ in the rhizome and the content in the rhizosphere soil, even though the content of $\mathrm{Zn}(57.8 \mathrm{mg} / \mathrm{Kg})$ in the rhizosphere soil at E9 points is significantly reduced compared to 
https://doi.org/10.5194/soil-2021-37

Preprint. Discussion started: 17 May 2021

(c) Author(s) 2021. CC BY 4.0 License.

285 the other two points, but at this time the content of $\mathrm{Zn}(28.93 \mathrm{mg} / \mathrm{Kg})$ in the rhizome is still close to the concentration of the other two points (BCF is the highest, 0.5). Besides, we observed a negative correlation between $\mathrm{Ca}$ and $\mathrm{Cu}$ content in the rhizome and content in the rhizosphere soil. The $\mathrm{Ca}$ content of the rhizosphere soil in C0 points was the lowest compared to E5 and E9 $(7737.04 \mathrm{mg} / \mathrm{Kg})$, while the average content of $\mathrm{Ca}$ was the highest in the rhizome at $\mathrm{C} 0$ points $(3009.31 \mathrm{mg} / \mathrm{Kg}, \mathrm{BCF}$ is also the highest, 0.39). Cu content in E9-point rhizosphere soil was the lowest compared to C0 and E5 (30.73 $\mathrm{mg} / \mathrm{Kg})$, while the average content of $\mathrm{Cu}$ in $\mathrm{E} 9$ rhizome was highest $(12.10 \mathrm{mg} / \mathrm{Kg}$, BCF is also the highest, 0.39).

Table 6 The elemental content of rhizosphere and bulk soil

\begin{tabular}{|c|c|c|c|c|c|c|}
\hline & $\mathrm{CON}$ & $\mathrm{COR}$ & E5N & E5R & E9N & E9R \\
\hline $\mathrm{Na}$ & $9761.90 \pm 379.29$ & $10062.96 \pm 582.96$ & $9402.22 \pm 442.66$ & $9584.44 \pm 387.89$ & $4566.67 \pm 732.07$ & $4616.67 \pm 1139.06$ \\
\hline $\mathrm{Mg}$ & $9988.10 \pm 550.48$ & $10125.93 \pm 434.54$ & $11575.56 \pm 939.56$ & $11331.11 \pm 745.30$ & $8254.76 \pm 1355.81$ & $8666.67 \pm 1991.41$ \\
\hline $\mathrm{Al}$ & $82252.38 \pm 694.12$ & $80866.67 \pm 396.51$ & $81560.00 \pm 4819.69$ & $82288.89 \pm 3469.89$ & $78290.48 \pm 5217.91$ & $79308.33 \pm 7932.01$ \\
\hline $\mathrm{Si}$ & $292583.3 \pm 2900.21$ & $291281.5 \pm 1997.71$ & $289817.8 \pm 6451.98$ & $288882.2 \pm 4545.45$ & $293026.2 \pm 10751.79$ & $293091.7 \pm 16322.97$ \\
\hline $\mathrm{P}$ & $1552.33 \pm 71.09$ & $1905.22 \pm 254.27$ & $945.76 \pm 483.53$ & $1243.22 \pm 396.46$ & $628.29 \pm 61.59$ & $647.83 \pm 122.56$ \\
\hline $\mathrm{S}$ & $171.86 \pm 24.20$ & $186.89 \pm 22.51$ & $139.22 \pm 29.50$ & $152.07 \pm 36.25$ & $214.52 \pm 47.86$ & $234.58 \pm 102.74$ \\
\hline $\mathrm{Cl}$ & $63.00 \pm 3.76$ & $82.37 \pm 9.14$ & $76.49 \pm 19.58$ & $115.56 \pm 35.97$ & $101.45 \pm 24.96$ & $153.75 \pm 39.69$ \\
\hline $\mathrm{K}$ & $22378.57 \pm 1030.94$ & $22688.89 \pm 932.74$ & $22300.00 \pm 1279.94$ & $22800.00 \pm 925.65$ & $15742.86 \pm 2000.62$ & $17104.17 \pm 2810.44$ \\
\hline $\mathrm{Ca}$ & $6547.62 \pm 637.95$ & $7737.04 \pm 1234.28$ & $8666.67 \pm 584.59$ & $8144.44 \pm 657.88$ & $11602.38 \pm 5093.32$ & $13133.33 \pm 6857.97$ \\
\hline $\mathrm{Fe}$ & $37178.57 \pm 1351.84$ & $36374.07 \pm 805.67$ & $43906.67 \pm 4110.46$ & $41424.44 \pm 3526.42$ & $41526.19 \pm 5023.22$ & $43266.67 \pm 6758.65$ \\
\hline $\mathrm{Sc}$ & $13.64 \pm 1.07$ & $13.01 \pm 0.98$ & $15.39 \pm 1.39$ & $14.66 \pm 1.31$ & $13.47 \pm 1.75$ & $14.54 \pm 2.36$ \\
\hline $\mathrm{Ti}$ & $4648.05 \pm 72.97$ & $4545.11 \pm 72.93$ & $4815.68 \pm 188.42$ & $4680.60 \pm 152.70$ & $4609.77 \pm 196.05$ & $4674.25 \pm 253.11$ \\
\hline V & $116.20 \pm 3.68$ & $113.36 \pm 1.85$ & $130.65 \pm 9.56$ & $125.08 \pm 7.90$ & $108.70 \pm 11.82$ & $112.56 \pm 16.09$ \\
\hline $\mathrm{Cr}$ & $85.82 \pm 2.42$ & $83.25 \pm 1.65$ & $109.49 \pm 6.40$ & $101.33 \pm 8.48$ & $82.78 \pm 7.37$ & $86.01 \pm 9.78$ \\
\hline $\mathrm{Mn}$ & $339.98 \pm 27.44$ & $345.78 \pm 24.88$ & $668.54 \pm 236.41$ & $566.80 \pm 222.76$ & $701.79 \pm 85.58$ & $645.35 \pm 105.16$ \\
\hline Co & $31.53 \pm 3.58$ & $34.40 \pm 9.59$ & $27.32 \pm 2.21$ & $29.53 \pm 5.13$ & $32.22 \pm 7.33$ & $40.01 \pm 22.72$ \\
\hline $\mathrm{Ni}$ & $35.69 \pm 2.09$ & $35.71 \pm 1.64$ & $47.35 \pm 6.22$ & $42.94 \pm 5.46$ & $41.77 \pm 4.07$ & $44.27 \pm 5.10$ \\
\hline $\mathrm{Cu}$ & $36.98 \pm 1.35$ & $37.08 \pm 1.49$ & $40.32 \pm 1.75$ & $40.26 \pm 1.71$ & $30.78 \pm 3.09$ & $30.73 \pm 3.74$ \\
\hline $\mathrm{Zn}$ & $95.02 \pm 5.00$ & $98.84 \pm 9.49$ & $109.78 \pm 11.18$ & $107.31 \pm 14.86$ & $66.02 \pm 16.41$ & $57.80 \pm 41.89$ \\
\hline
\end{tabular}


https://doi.org/10.5194/soil-2021-37

Preprint. Discussion started: 17 May 2021

(c) Author(s) 2021. CC BY 4.0 License.

\begin{tabular}{|c|c|c|c|c|c|c|}
\hline $\mathrm{Ga}$ & $19.18 \pm 0.63$ & $19.29 \pm 0.60$ & $20.11 \pm 1.58$ & $20.20 \pm 0.94$ & $18.28 \pm 2.34$ & $19.94 \pm 3.58$ \\
\hline As & $5.64 \pm 0.67$ & $4.64 \pm 1.77$ & $7.42 \pm 0.40$ & $5.98 \pm 1.53$ & $15.28 \pm 2.30$ & $13.78 \pm 5.38$ \\
\hline $\mathrm{Br}$ & $1.26 \pm 0.15$ & $1.41 \pm 0.34$ & $1.77 \pm 0.73$ & $1.66 \pm 0.72$ & $1.36 \pm 0.29$ & $1.26 \pm 0.62$ \\
\hline $\mathrm{Rb}$ & $121.32 \pm 5.31$ & $121.44 \pm 5.82$ & $124.14 \pm 9.11$ & $123.73 \pm 5.79$ & $103.83 \pm 14.45$ & $110.15 \pm 19.05$ \\
\hline $\mathrm{Sr}$ & $170.39 \pm 15.85$ & $177.76 \pm 19.42$ & $164.80 \pm 5.63$ & $166.00 \pm 5.95$ & $96.65 \pm 7.97$ & $99.66 \pm 11.17$ \\
\hline $\mathrm{Y}$ & $28.74 \pm 0.57$ & $28.53 \pm 0.49$ & $28.54 \pm 1.02$ & $28.78 \pm 0.69$ & $35.36 \pm 1.41$ & $34.24 \pm 1.25$ \\
\hline $\mathrm{Zr}$ & $247.83 \pm 12.67$ & $242.94 \pm 8.95$ & $205.87 \pm 7.43$ & $217.86 \pm 13.28$ & $277.37 \pm 38.78$ & $257.08 \pm 47.52$ \\
\hline $\mathrm{Ba}$ & $600.63 \pm 26.14$ & $593.47 \pm 22.20$ & $620.35 \pm 27.90$ & $616.08 \pm 22.53$ & $496.58 \pm 56.47$ & $511.20 \pm 74.30$ \\
\hline $\mathrm{La}$ & $32.69 \pm 3.21$ & $35.80 \pm 2.27$ & $35.62 \pm 3.65$ & $35.80 \pm 4.11$ & $44.51 \pm 2.50$ & $45.45 \pm 3.40$ \\
\hline $\mathrm{Hf}$ & $7.05 \pm 0.38$ & $6.90 \pm 0.28$ & $6.03 \pm 0.25$ & $6.30 \pm 0.45$ & $7.55 \pm 0.96$ & $6.98 \pm 1.24$ \\
\hline $\mathrm{Pb}$ & $36.89 \pm 1.87$ & $35.56 \pm 2.44$ & $34.75 \pm 3.99$ & $34.93 \pm 4.37$ & $29.79 \pm 2.12$ & $28.55 \pm 2.18$ \\
\hline $\mathrm{Ce}$ & $71.95 \pm 3.52$ & $74.12 \pm 5.60$ & $72.50 \pm 5.65$ & $72.68 \pm 6.17$ & $84.36 \pm 3.53$ & $86.17 \pm 4.10$ \\
\hline Th & $11.85 \pm 0.77$ & $12.50 \pm 0.70$ & $11.90 \pm 1.65$ & $12.22 \pm 0.85$ & $13.33 \pm 1.51$ & $13.84 \pm 3.15$ \\
\hline $\mathrm{Cd}$ & $0.35 \pm 0.14$ & $0.38 \pm 0.10$ & $0.39 \pm 0.15$ & $0.44 \pm 0.042$ & $0.31 \pm 0.15$ & $0.39 \pm 0.049$ \\
\hline $\mathrm{TN}$ & $1627.78 \pm 0.0046$ & $2148.23 \pm 0.016$ & $1365.80 \pm 0.14$ & $1673.47 \pm 0.035$ & $1318.25 \pm 0.02$ & $1502.62 \pm 0.15$ \\
\hline OM & $2.78 \pm 0.06$ & $3.66 \pm 0.24$ & $2.35 \pm 0.67$ & $2.78 \pm 0.62$ & $1.82 \pm 0.52$ & $2.02 \pm 0.33$ \\
\hline $\mathrm{pH}$ & $5.97 \pm 0.14$ & $6.46 \pm 0.61$ & $6.51 \pm 0.50$ & $6.02 \pm 0.43$ & $7.55 \pm 0.50$ & $7.21 \pm 0.66$ \\
\hline
\end{tabular}

295 The inorganic element content units are $\mathrm{mg} / \mathrm{kg}$. The value after " \pm " is the standard deviation, keep all data in two places. $\mathrm{C} 0 \mathrm{~N}$ is the bulk soil of the $\mathrm{C} 0$ sample, $\mathrm{C} 0 \mathrm{R}$ is the rhizosphere soil of the $\mathrm{C} 0$ sample, E5N is the bulk soil of the E5 sample, E5R is the rhizosphere soil of the E5 sample, E9N is the bulk soil of the E9 sample, and E9R is the rhizosphere soil of the E9 sample. 
https://doi.org/10.5194/soil-2021-37

Preprint. Discussion started: 17 May 2021

(c) Author(s) 2021. CC BY 4.0 License.

Sol EG

A

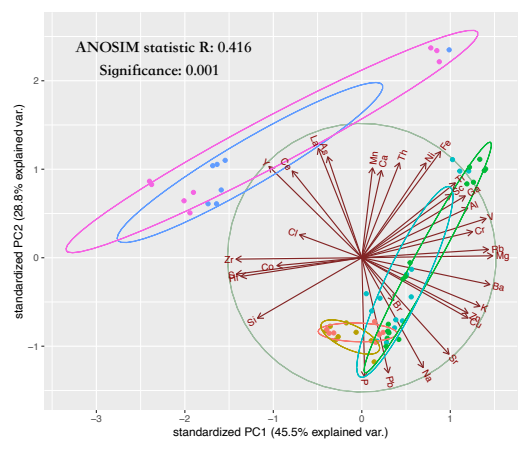

B

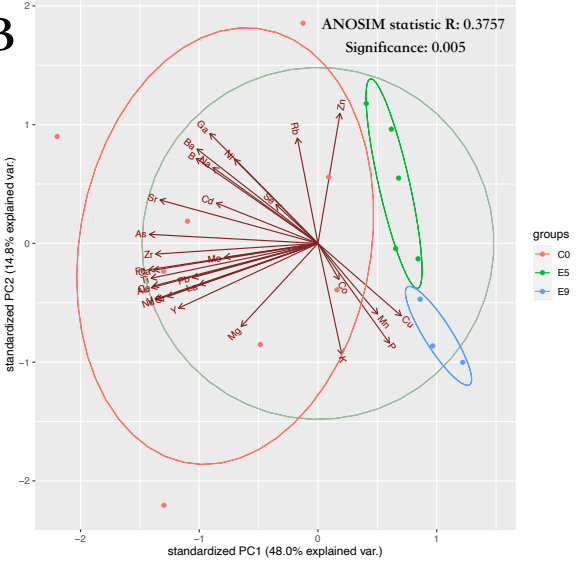

Figure 6 PCA. PCA based on a standardized distance matrix of elemental data. A is the soil sample, $\mathrm{C} 0 \mathrm{~N}$ is the bulk soil of the $\mathrm{C} 0$ sample, $\mathrm{C} 0 \mathrm{R}$ is the rhizosphere soil of the $\mathrm{C} 0$ sample, $\mathrm{E} 5 \mathrm{~N}$ is the bulk soil of the E5 sample, E5R is the rhizosphere soil of the E5 sample, E9N is the bulk soil of the E9 sample, and E9R is the rhizosphere soil of the E9 sample. B is a sample of the rhizomes of Ligusticum chuanxiong Hort. The ANOSIM similarity test showed significant differences between groups at a $95 \%$ confidence level $(\mathrm{P}<0.05)$.

Table 7 bioconcentration factors

\begin{tabular}{llll}
\hline & C0 & E5 & E9 \\
\hline $\mathrm{Na}$ & 0.14 & 0.15 & 0.12 \\
$\mathrm{Mg}$ & 0.22 & 0.18 & 0.22 \\
$\mathrm{P}$ & 2.24 & 3.66 & 7.4 \\
$\mathrm{~K}$ & 0.34 & 0.29 & 0.54 \\
$\mathrm{Ca}$ & 0.39 & 0.24 & 0.16 \\
$\mathrm{Fe}$ & 0 & 0 & 0 \\
$\mathrm{Ti}$ & 0 & 0 & 0 \\
$\mathrm{~V}$ & 0 & 0 & 0 \\
$\mathrm{Cr}$ & 0 & 0 & 0 \\
$\mathrm{Mn}$ & 0.07 & 0.05 & 0.06 \\
$\mathrm{Co}$ & 0.07 & 0.14 & 0.07 \\
$\mathrm{Ni}$ & 0.06 & 0.04 & 0.04
\end{tabular}


https://doi.org/10.5194/soil-2021-37

Preprint. Discussion started: 17 May 2021

(c) Author(s) 2021. CC BY 4.0 License.

$\begin{array}{llll}\mathrm{Cu} & 0.24 & 0.24 & 0.39 \\ \mathrm{Zn} & 0.29 & 0.28 & 0.5 \\ \mathrm{Ga} & 0.06 & 0.04 & 0.03 \\ \mathrm{As} & 0.03 & 0.01 & 0 \\ \mathrm{Rb} & 0.06 & 0.08 & 0.03 \\ \mathrm{Sr} & 0.12 & 0.08 & 0.09 \\ \mathrm{Y} & 0 & 0 & 0 \\ \mathrm{Zr} & 0 & 0 & 0 \\ \mathrm{Ba} & 0.02 & 0.01 & 0.01 \\ \mathrm{La} & 0 & 0 & 0 \\ \mathrm{~Pb} & 0.01 & 0.01 & 0.01 \\ \mathrm{Ce} & 0 & 0 & 0\end{array}$

\subsection{The rate of change in the background of chemical elements}

The background value of the chemical elements of the soil is controlled by the soil parent material, which reflects the natural geological background. We calculated the background change rate of chemical elements in center-zone and the eastern extension zone (Figure 7). Results showed significant increases in $\mathrm{Al}, \mathrm{Fe}, \mathrm{Mg}, \mathrm{Si}, \mathrm{Ca}, \mathrm{K}$, and $\mathrm{Na}$ in the soil. Besides, the background change rate of other chemical elements in the soil in the center zone remained relatively small variation, and only content of Mn significantly changed, decreasing by $55.46 \%$. P and $\mathrm{Cu}$ in the eastern extension zone had a significant increase by $117.1 \%$ and $67.67 \%$, respectively, and the $\mathrm{Ni}$ and Mo fluctuated mainly with the geographical coordinates, indicating a specific geographical heterogeneity. Throughout the study area, the overall content of other potentially harmful and rare earth elements increased in the soil, excluding Ba, Co and La. Besides, abnormal increases were found in $\mathrm{Zn}$ at E15, As at E19 and Th at E10. It is explained that there are changes in soil element composition characteristics in the cultivation of L.chuanxiong, which is mainly due to plant cultivation and its artificial intervention, such as fertilization, irrigation. 

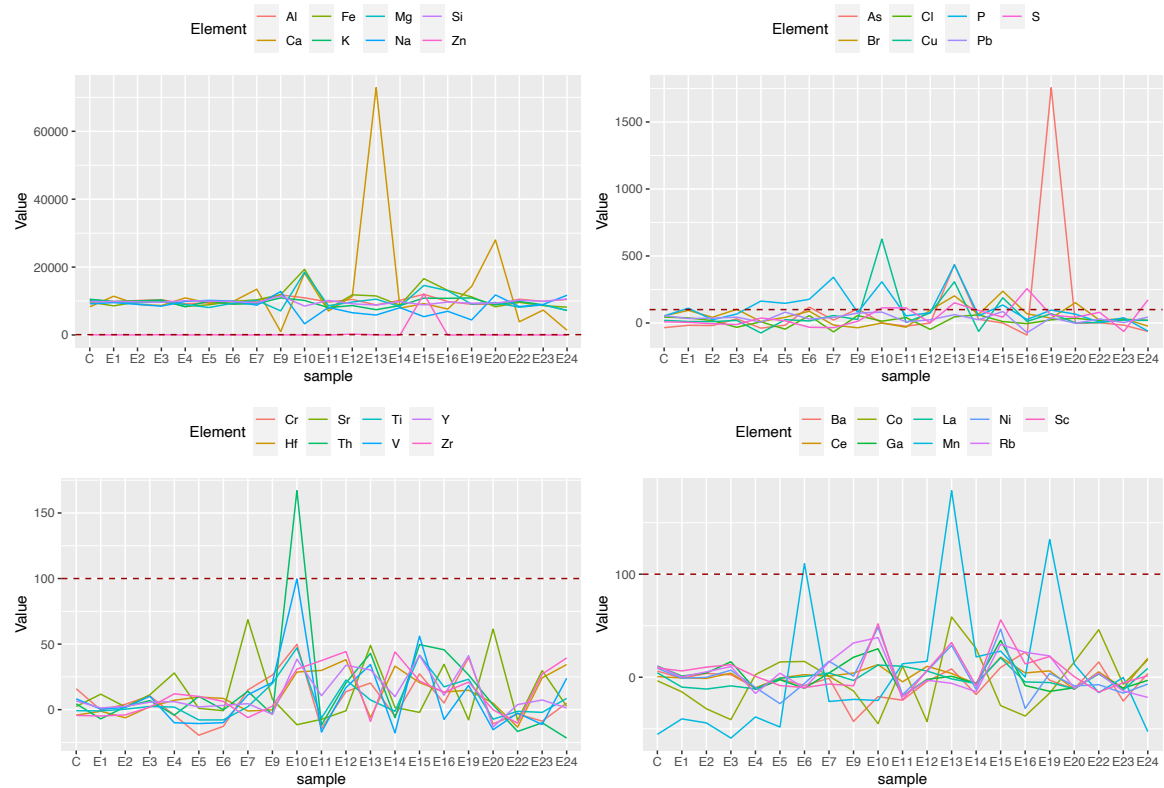

Figure 7 The change rate of background chemical elements. $\mathrm{C}$ is the average value of the center-zone. The red dotted line is a change rate of 100 , and exceeding the red dotted line indicates a significant increase in the element's content.

\section{DISSCUSION}

\subsection{The geographical heterogeneity of soil elements in center and eastern extension zone}

Since L.chuanxiong is a medicinal plant with typical regional effects, we investigated the variation of elements in the bulk soil in the traditional central zone of L.chuanxiong (Shiyan Town, Dujiangyan City) and the eastern extension zone. The clustering analysis of soil elements shows that there is significant regional heterogeneity in the study zone and can be divided into at least three cluster groups (Cluster1 includes all central zone samples and E1 to E10, E15, E22, E24 to E27; Cluster2 includes E11 to E14, E16 to E19; Cluster3 includes E20, E21, E23, E28). Moreover, some samples of the eastern extension zone are very close to the central zone's soil element features, indicating that the soil characteristics of the Daodi-zone are not limited to the existing region.

The Eastern Extension zone covers the plain areas of western Sichuan and the hilly and low mountain areas of central Sichuan (Figure 1, E1 to E28). Rock bases in this region are diverse due to the deformation and fracture of geological structure caused by topographic uplift and deposition (Liu et al., 2012). Most of the elemental concentrations in Cluster1 are higher than Cluster2 and Cluster 3. On the 
https://doi.org/10.5194/soil-2021-37

Preprint. Discussion started: 17 May 2021

(c) Author(s) 2021. CC BY 4.0 License.

one hand, some samples in Cluster1 are close to the center-zone (including E1 to E10), and their soil sources are consistent with the central region, characterized by the high maturity of paddy soil and the magmatic rock as a raw material (Tang et al., 2005). On the other hand, cluster1 has samples such as E24 to E27 that are geographically far from the center-zone, which may be due to the short history of cultivating L.chuanxiong in the local region(PENG et al., 2007). Local farmers influence the proportion structure of the original nutrients in the soil by using the soil management methods of the L.chuanxiong, which causes the local soil to be similar to the elements of the central region to some extent.

Besides, E10 sample points and subsequent sample points interval Longquan Mountain chain, due to the laboratory early investigation (Fang et al., 2020) of soil elements with the central zone as the starting point along the longitude south of the change characteristics, found that S1 to S6 sample points were similar with the central region. The S6 and subsequent sample points are also separate in the Longquan Mountains, so the results of the two studies suggest that the composition of soil elements will change significantly due to the elevated terrain, indicating that the range of L.chuanxiong' Daodi-zone is likely to be related to the distribution height of the Longquan Mountain chain.

The soil parent material of sample points in Cluster2, which extends mainly from the Tuojiang River to the Fujiang River, is mainly composed of calcareous purple sandstone and is rich in calcium (Zheng-An et al., 2010), which interprets that the average Ca content in Cluster 2 is the highest in all groups. Cluster3, similar to Cluster2, is also mainly affected by calcareous purple sandstone, so Ca concentration levels are also high. The linear regression analysis shows that the center-zone's elemental similarity coefficient is mainly positively related to altitude and negatively related to $\mathrm{pH}$ and $\mathrm{OM}$.

\subsection{The regional heterogeneity of soil elements affects the accumulation of active ingredients}

The central zone where C0 located is a recognized Daodi-zone of L.chuanxiong. The samples' soil elements in Cluster 2 and Cluster 3 are significantly different from the central region, but samples in the eastern extension zone in Cluster 1 are more similar to the central zone. Therefore, to screen the characteristic soil elements that will significantly affect the accumulation of metabolites in the rhizomes of L.chuanxiong, we selected E5 and E9 in Cluster1, which belong to two differnet cluster trees, and C0 in the central zone to conduct field cultivation experiments on L.chuanxiong (in cluster trees, E5 is closer to the sample in the central-zone, and E9 is farther away). We found the ligustilide was significantly higher than $\mathrm{E} 9$ in the rhizome sample at the $\mathrm{C}$, and there was no significant difference with $\mathrm{E} 5$, so was 
https://doi.org/10.5194/soil-2021-37

Preprint. Discussion started: 17 May 2021

(c) Author(s) 2021. CC BY 4.0 License.

the moisture content in the rhizome. Since the report shows that $\mathrm{Zn}$ is not conducive to the synthetic accumulation of Ligustilide and Senkyunolide A, we observed that Zn's concentration in rhizomes of the three sites were close to each other, but Zn's BCF was the highest in the E9 sample points. We speculated that during the process of L.chuanxiong strengthen $\mathrm{Zn}$ 's absorption, resulting in the uneven distribution in the rhizome at E9, thus affecting the synthesis ability of secondary metabolites in the rhizome(Chen et al., 2020). Therefore, high Zn's BCF of L.chuanxiong at E9 may be one reason why secondary metabolites' content is different from $\mathrm{C} 0$ and $\mathrm{E} 5$.

In addition, the study showed that the synthetic accumulation of secondary metabolites in L.chuanxiong's rhizome was positively correlated with the soil organic matter(Fan et al., 2013). In this experiment, the soil organic matter content in $\mathrm{C} 0$ and $\mathrm{E} 5$ was close, and the $\mathrm{E} 9$ was lowest, whereas the content of most active ingredients in $\mathrm{C} 0$ was similar to $\mathrm{E} 5$ but higher than $\mathrm{E} 9$. It is indicated that the more similar the characteristics of the soil elements, the more similar the characteristics of the content of secondary metabolites composition obtained by cultivation.

Since inorganic elements also play an essential role in plant metabolism(Zhang et al., 2015;Wang et al., 2020;Abou-Arab and Abou Donia, 2000; Wen-Lan et al., 2015), we observed a significant positive correlation between Se and Senkyunolide I, Senkyunolide H and Ligustilide in the rhizomes of L.chuanxiong, possibly because Se improves the overall physical and chemical properties of plants, improves secondary metabolites, and helps plants overcome the stress of $\mathrm{Cr}$ in the soil(Handa et al., 2019). Besides, Mn in the rhizome was significantly negatively associated with Conferyl ferulate and Ligustilide, positively related to Ferulic Acid, and $\mathrm{Sr}$ and Ligustilide in the rhizome were positively related significantly. This may be since heavy metals play the role of non-biological stimulates in biosynthesis, affecting plants' secondary metabolic processes (Lajayer et al., 2017a). Moreover, reports indicate that medicinal plant with invigorating blood circulation, such as L.chuanxiong, is usually rich in $\mathrm{K}, \mathrm{Na}$ and $\mathrm{Mg}$, but deficient in $\mathrm{Mn}(\mathrm{Wu}, 2017)$. Among them, $\mathrm{Na}$ and $\mathrm{K}$ are essential for acid-base balance. $\mathrm{K}$ is responsible for dilating blood vessels, while $\mathrm{Mn}$ at high concentrations can cause blood vessels to constrict (He and MacGregor, 2008;Aschner and Aschner, 2005). Mg is closely related to the activation of enzymes and calms the nervous system (Jahnen-Dechent and Ketteler, 2012). K and Mg in medicinal plants also play a detox and live blood role. In this study, the average concentration of soil nutrients such as $\mathrm{Na}, \mathrm{Mg}$ and $\mathrm{K}$ in center zone were significantly higher than the background values, and $\mathrm{Na}, \mathrm{Mg}$ and 
https://doi.org/10.5194/soil-2021-37

Preprint. Discussion started: 17 May 2021

(c) Author(s) 2021. CC BY 4.0 License.

K were significantly higher than E9 samples in the rhizosphere and bulk soils of E5 samples, so this may be a condition for the production of high-quality L.chuanxiong.

\subsection{Increased risk of heavy metal pollution in production zone}

During the long-term cultivation process, the content and composition of elements in the soil usually change. Besides, climate change and industrial activities can also impact the soil elements. By analyzing the spatial heterogeneity of deep soil elements in the study zone, we evaluated soil elements' changing characteristics in the central and eastern extension zone. In the rice paddies, soil samples in the centerzone, $\mathrm{Cu}, \mathrm{Cr}, \mathrm{Pb}$ and $\mathrm{Zn}$, were all higher than the local soil background values, although the soil's heavy metal elements did not exceed the standard. The background change rate of chemical elements also shows that the content of most potentially harmful elements and rare earth elements has increased, indicating that the soil environmental safety in the study zone is gradually decreasing (Ren et al., 2005; Yang et al., 2018b). It is suggested that we need to strengthen the environmental protection work in the L.chuanxiong planting area to avoid the decline of safety and the reduction of the available area in the production zone.

Based on the above results, we believe that there is a geo-boundary of the suitable elemental zone of L.chuanxiong, which can indicate the natural boundary of the high-quality L.chuanxiong's Daodi-zone. In pre-laboratory studies, Fang et al. found that the soil elements extending $60 \mathrm{~km}$ southward from the center-zone (Dujiangyan Shiyang Town) to the territory of L.chuanxiong were the Daodi-zone of L.chuanxiong, and found that $\mathrm{K}, \mathrm{Mg}, \mathrm{Mn}$ and $\mathrm{Rb}$ could be used as soil characteristic factors (Fang et al.) to evaluate the production zone of L.chuanxiong. In this experiment, we believe that the area extending 55 kilometres eastward along the latitude from the center-zone (Dujiangyan Shiyang Town) is the L.chuanxiong's Daodi-zone. Soils in this area are characterized by weak acidity, high $\mathrm{Na}, \mathrm{Al}, \mathrm{P}, \mathrm{Cu}, \mathrm{Zn}$, $\mathrm{Fe} / \mathrm{Mn}(116.82 \pm 20.88), \mathrm{Na} / \mathrm{K}(0.44 \pm 0.07)$ and $\mathrm{K} / \mathrm{Mg}(2.00 \pm 0.24)$ values, while $\mathrm{Zn} / \mathrm{Cu}(2.64 \pm 0.32)$ and $\mathrm{Ca} / \mathrm{P}$ have lower values $(8.38 \pm 3.6)$. Comparing the soil characteristics of the Daodi-zone in the two studies, they are rich in $\mathrm{Na}, \mathrm{Mg}, \mathrm{K}$ and low $\mathrm{Mn}$. Combined with the area's topography, the natural boundary of L.chuanxiong's Daodi-zone is located on the west and north sides of the Longquan Mountains (southwest to northeast) in both directions. The two studies did not cover the west and northerly aspects of the L.chuanxiong Daodi-zone because the west and north of Dujiangyan are right in the intersection of the Sichuan Basin and the surrounding mountains. Therefore, we think that 
https://doi.org/10.5194/soil-2021-37

Preprint. Discussion started: 17 May 2021

(c) Author(s) 2021. CC BY 4.0 License.

eastwards and southwards to about $60 \mathrm{~km}$ in the Longquan Mountains, respectively. Although all the study areas span the Tuojiang, Fujiang and Jialing rivers, they have not had a significant impact on the boundaries of the L.chuanxiong's Daodi-zone.

This study successfully verified that the Daodi-zone has natural boundaries, and it is feasible to identify the suitable growth area of plants based on the characteristic soil elements. We also suggest that the high-quality production zone for certain economic plants is limited to a particular region and that the dominant factor in this phenomenon is likely to be a specific combination of soil elements. This study also provides a favourable environmental zoning basis for other economic plants with smaller areas of origin.

\section{Data availability}

All data are included in the paper.

\section{Author contributions}

ZY, DH and QF designed the research. QF, HL, LK, QS performed the research. HL analysed the data,

and HL, HW, DH, XZ and GH wrote the paper.

\section{Competing interests}

The authors declare that they have no conflict of interest.

\section{Acknowledgements}

We are grateful to Shuhua Zhang, Fangqiong Li and Hongmei Jia for assistance during the sampling.

\section{$445 \quad$ Financial support}

This study was Supported by grants from the National Natural Science Foundation of China (81673553) , Key project at central government level: The ability establishment of sustainable use for valuable Chinese medicine resources (2060302), Project of Inheritance Studio of National Famous Experts of State Administration of TCM (NO. [2019] 41), "Xing Lin Scholars" Research Promotion 
https://doi.org/10.5194/soil-2021-37

Preprint. Discussion started: 17 May 2021

(c) Author(s) 2021. CC BY 4.0 License.

References

The Technical Specification for soil Environmental monitoring. China, M. o. E. a. E. o. t. P. s. R. o. (Ed.), 2004

Abou-Arab, A. A. K., and Abou Donia, M. A.: Heavy metals in Egyptian spices and medicinal plants and the effect of processing on their levels, Journal of Agricultural \& Food Chemistry, 48, 2300-2304, 2000.

Andrade, S. A., Silveira, A. P., and Mazzafera, P.: Arbuscular mycorrhiza alters metal uptake and the physiological response of Coffea arabica seedlings to increasing $\mathrm{Zn}$ and $\mathrm{Cu}$ concentrations in soil, Sci Total Environ, 408, 53815391, 10.1016/j.scitotenv.2010.07.064, 2010.

Aschner, J. L., and Aschner, M.: Nutritional aspects of manganese homeostasis, Molecular aspects of medicine, 26, 353-362, 2005

Bao, S.: Analysis of soiland agricultural chemistry, The third edition ed., China Agriculture Press, 2000.

Bonari, G., Monaci, F., Nannoni, F., Angiolini, C., and Protano, G.: Trace element uptake and accumulation in the medicinal herb Hypericum perforatum L. across different geolithological settings, Biological trace element research, 189, 267-276, 2019.

Bornø, M. L., Eduah, J. O., Müller-Stöver, D. S., and Liu, F.: Effect of different biochars on phosphorus (P) dynamics in the rhizosphere of Zea mays L.(maize), Plant and Soil, 431, 257-272, 2018.

Camacho-Cristóbal, J. J., Lunar, L., Lafont, F., Baumert, A., and González-Fontes, A. n.: Boron deficiency causes accumulation of chlorogenic acid and caffeoyl polyamine conjugates in tobacco leaves, Journal of Plant Physiology, $161,879-881,2004$.

Chakravarty, S., Dureja, V., and Bhattacharyya, G.: Removal of arsenic from groundwater using low cost ferruginous manganese ore, Water Research, 36, 625-632, 2002

Chen, J., Wei, F., Zheng, C., Wu, Y., and Adriano, D. C.: Background concentrations of elements in soils of China, Water, Air, and Soil Pollution, 57, 699-712, 1991.

Chen, Y., Zhang, C., Liao, X., Sha, X., Tao, S., Yuan, C., Xu, Z., and Fang, P.: Effects of Trace Elements on the Active Constituents of Ligusticum chuanxiong Hort, Journal of Henan Agricultural Sciences, 49, 35-43, 2020.

Chen, Z., Zhang, C., Gao, F., Fu, Q., Fu, C., He, Y., and Zhang, J.: A systematic review on the rhizome of Ligusticum chuanxiong Hort. (Chuanxiong), Food Chem Toxicol, 119, 309-325, 10.1016/j.fet.2018.02.050, 2018.

Cheng, H., Li, K., Li, M., Yang, K., Liu, F., and Cheng, X.: Geochemical background and baseline value of chemical elements in urban soil in China, Earth Sci. Front, 21, 265-306, 2014.

Fageria, V.: Nutrient interactions in crop plants, Journal of plant nutrition, 24, 1269-1290, 2001.

480 Fan, Q., Lan, T., Zheng, S., Liu, J., and Yuan, J.: Effects of No-tillage and Straw Covering on Soil Fertility, Yield and Quality of Ligusticum chuanxiong, 2013.

Fang, Q., Yan, Z., Lv, H., Jia, H., Zhang, S., Wang, H., and He, D.: Research on Natural Boundary of Traditional Geo-authentic Origin of Ligusticum chuanxiong via Soil Elements Characteristics Along Same Longitude, Chinese Journal of Experimental Traditional Medical Formulae, 26(18), 145 153, 2020.

485 Guerriero, G., Berni, R., Muñoz-Sanchez, J. A., Apone, F., Abdel-Salam, E. M., Qahtan, A. A., Alatar, A. A., Cantini, C., Cai, G., and Hausman, J.-F.: Production of plant secondary metabolites: Examples, tips and suggestions for biotechnologists, Genes, 9, 309, 2018.

Guo, L. P., Wang, S., Zhang, J., Yang, G., Zhao, M. X., Ma, W. F., Zhang, X. B., Li, X., Han, B. X., Chen, N., and Huang, L. Q.: Effects of ecological factors on secondary metabolites and inorganic elements of Scutellaria baicalensis and analysis of geoherblism, Science China-Life Sciences, 56, 1047-1056, 10.1007/s11427-013-4562-5, 2013.

Handa, N., Kohli, S. K., Sharma, A., Thukral, A. K., Bhardwaj, R., Abd_Allah, E. F., Alqarawi, A. A., and Ahmad, P.: Selenium modulates dynamics of antioxidative defence expression, photosynthetic attributes and secondary 
https://doi.org/10.5194/soil-2021-37

Preprint. Discussion started: 17 May 2021

(c) Author(s) 2021. CC BY 4.0 License.

metabolites to mitigate chromium toxicity in Brassica juncea L. plants, Environmental and Experimental Botany,

161, 180-192, 2019

He, F. J., and MacGregor, G. A.: Beneficial effects of potassium on human health, Physiologia plantarum, 133, 725$735,2008$.

He, Y., Ren, L., Tang, W., Qin, B., Zhou, X., Tao, X., and Ma, Z.: Soil geochemical characteristics from Chengdu economic zone and implications for soil classification, Geochimica, 35, 311-318, 2006.

500 Hou, J.: The study of the quality resources of Ligusitcum chuanxiong Hort's species in different origin, Chengdu: Chengdu University of Traditional Chinese Medicine, 2007.

Huang, Y., and Jiang, X.: Field-observed phenomena of seismic liquefaction and subsidence during the 2008 Wenchuan earthquake in China, Natural Hazards, 54, 839-850, 2010.

Jahnen-Dechent, W., and Ketteler, M.: Magnesium basics, Clinical kidney journal, 5, i3-i14, 2012.

505 Khan, M., Shirazi, M., Khan, M. A., Mujtaba, S., Islam, E., Mumtaz, S., Shereen, A., Ansari, R., and Ashraf, M. Y.: Role of proline, K/Na ratio and chlorophyll content in salt tolerance of wheat (Triticum aestivum L.), Pak. J. Bot, 41, 633-638, 2009.

Lajayer, B. A., Ghorbanpour, M., and Nikabadi, S.: Heavy metals in contaminated environment: destiny of secondary metabolite biosynthesis, oxidative status and phytoextraction in medicinal plants, Ecotoxicology and Environmental

Safety, 145, 377-390, 2017a.

Lajayer, H. A., Savaghebi, G., Hadian, J., Hatami, M., and Pezhmanmehr, M.: Comparison of copper and zinc effects on growth, micro-and macronutrients status and essential oil constituents in pennyroyal (Mentha pulegium L.), Brazilian Journal of Botany, 40, 379-388, $2017 \mathrm{~b}$.

Li, Y., Kong, D., Fu, Y., Sussman, M. R., and Wu, H.: The effect of developmental and environmental factors on secondary metabolites in medicinal plants, Plant Physiology and Biochemistry, 148, 80-89, 2020.

Liu, S., Deng, B., Li, Z., and Sun, W.: Architecture of basin-mountain systems and their influences on gas distribution: A case study from the Sichuan basin, South China, Journal of Asian Earth Sciences, 47, 204-215, 2012.

Liu, W., Liu, J. J., Yin, D. X., and Zhao, X. W.: Influence of Ecological Factors on the Production of Active Substances in the Anti-Cancer Plant Sinopodophyllum hexandrum (Royle) TS Ying, PLoS One, 10, e0122981,

\section{$520 \quad$ ARTN e0122981}

10.1371/journal.pone.0122981, 2015.

Ma, D., Ma, Y., Zhang, L., and Yang, Z.: The Comparison of the volatile oil composition of the three differentorigin Ligusticum chuanxiong Hort. and its near-lying plant Ligusticum sinense Oliv., Modern Chinese Medicine, 11, 20-22, 2009.

Ma, M., Gao, Y., Song, X., Green, S. M., Xiong, B., Dungait, J. A. J., Peng, T., Quine, T. A., Wen, X., and He, N.: Migration and leaching characteristics of base cation: indicating environmental effects on soil alkalinity in a karst area, Environmental Science and Pollution Research, 2018.

Macel, M., Lawson, C. S., Mortimer, S. R., Šmilauerova, M., Bischoff, A., Crémieux, L., Doležal, J., Edwards, A. R., Lanta, V., and Bezemer, T. M.: Climate vs. soil factors in local adaptation of two common plant species, Ecology, boron to shape morphological processes in plants, Journal of experimental botany, 71, 1681-1693, 2020.

Meyer, D., and Buchta, C.: proxy: Distance and Similarity Measures. 2020.

Oksanen, J., Blanchet, F. G., Kindt, R., Legendre, P., Minchin, P., O’hara, R., Simpson, G., Solymos, P., Stevens,

535 M., and Wagner, H.: Community ecology package, R package version, 2, 2013.

PENG, G.-z., PENG, J., and XIONG, Z.-q.: Ecological Adaptability Division of Ligusticum chuanxiong hort. in Sichuan Basin, Chinese Journal of Agrometeorology, 02, 2007. 
https://doi.org/10.5194/soil-2021-37

Preprint. Discussion started: 17 May 2021

(c) Author(s) 2021. CC BY 4.0 License.

Ren, S., Shao, Y., Gao, B., and Wang, D.: Effects of Long-term Located Fertilization on Heavy-metal Content of Soil, Journal of Soil and Water Conservation, 19, 96-99, 2005.

540 Santamaría, L., Figuerola, J., Pilon, J., Mjelde, M., Green, A. J., De Boer, T., King, R., and Gornall, R.: Plant performance across latitude: the role of plasticity and local adaptation in an aquatic plant, Ecology, 84, 2454-2461, 2003.

Senbayram, M., Gransee, A., Wahle, V., and Thiel, H.: Role of magnesium fertilisers in agriculture: plant-soil continuum, Crop and Pasture Science, 66, 1219-1229, 2016.

Singh, V., Agrawal, H. M., Joshi, G. C., Sudershan, M., and Sinha, A. K.: Elemental profile of agricultural soil by the EDXRF technique and use of the Principal Component Analysis (PCA) method to interpret the complex data, Applied radiation and isotopes: including data, instrumentation and methods for use in agriculture, industry and medicine, 69, 969-974, 2011.

Tang, W., Jin, L., and Zhou, X.: Reference geochemical values of elements in soil of Chengdu city and their implications, Geophys Geochem Explor, 29, 71-83, 2005.

Team, R. C.: R: A language and environment for statistical computing, 2013.

Van der Putten, W., Anderson, J., Bardgett, R. D., Behan-Pelletier, V., Bignell, D., Brown, G., Brown, V., Brussaard, L., Hunt, H., and Ineson, P.: Ecosystem processes in natural and managed terrestrial soils and the role of soil organisms in the sustainable delivery of ecosystem goods and services, in: Sustaining biodiversity and ecosystem services in soils and sediments, 15-43, 2004

Wang, L., Xiong, F., Yang, L., Xiao, Y., and Zhou, G.: A Seasonal Change of Active Ingredients and Mineral Elements in Root of Astragalus membranaceus in the Qinghai-Tibet Plateau, Biol Trace Elem Res, 1-10, 10.1007/s12011-020-02486-0, 2020.

Wang, Y.: Chinese Pharmacopoeia. In: China Standardization, TCM, B. C. M. I. o. C. (Ed.), No.73, 2015.

560 Wei, T., Simko, V., Levy, M., Xie, Y., Jin, Y., and Zemla, J.: Package 'corrplot', Statistician, 56, e24, 2017.

Wen, B., Ren, S., Zhang, Y., Duan, Y., Shen, J., Zhu, X., Wang, Y., Ma, Y., Zou, Z., and Fang, W.: Effects of geographic locations and topographical factors on secondary metabolites distribution in green tea at a regional scale, Food Control, 110, 106979, 2020.

Wen-Lan, L., Xue, Z., Xin-Xin, Y., Shuai, W., Lin, Z., Huan-Jun, Z., Yong-Rui, B., Chen-Feng, J., Ning, C., and

Zheng, X.: Species classification and bioactive ingredients accumulation of BaiJiangCao based on characteristic inorganic elements analysis by inductively coupled plasma-mass spectrometry and multivariate analysis, Pharmacognosy magazine, 11, 756, 2015.

Wu, Z.: Research on the Contents and Efficacy of Eight Kinds of Elements in 202 traditional exercise injury chinese medicine, Master, Taiyuan University of Technology, Taiyuan, 2017.

570 Yang, L., Wen, K.-S., Ruan, X., Zhao, Y.-X., Wei, F., and Wang, Q.: Response of plant secondary metabolites to environmental factors, Molecules, 23, 762, 2018a.

Yang, Q., Li, Z., Lu, X., Duan, Q., Huang, L., and Bi, J.: A review of soil heavy metal pollution from industrial and agricultural regions in China: Pollution and risk assessment, Sci Total Environ, 642, 690-700, 10.1016/j.scitotenv.2018.06.068, 2018b.

575 Yang, X., Post, W. M., Thornton, P. E., and Jain, A.: The distribution of soil phosphorus for global biogeochemical modeling, Biogeosciences, 10, 2013.

YIN, L., PENG, Y., CHEN, H.-p., LIU, R., FAN, D.-q., and LIU, Y.-p.: Comparison of the Content of Phenolic Acids in Ligusticum chuanxiong from New and Traditional Producing Areas and the Connotation of Division Grades, Chinese Journal of Experimental Traditional Medical Formulae, 11, 2013.

580 Zhang, J., Zhang, Z., Wang, Y., Zuo, Y., and Cai, C.: Environmental impact on the variability in quality of Gentiana rigescens, a medicinal plant in southwest China, Global Ecology and Conservation, 24, e01374, 2020. 
https://doi.org/10.5194/soil-2021-37

Preprint. Discussion started: 17 May 2021

(c) Author(s) 2021. CC BY 4.0 License.

Son. EG

Zhang, W., Ouyang, Z., Zhao, M., Wei, Y., Peng, H., Wang, Q., and Guo, L.: The influences of inorganic elements in soil on the development of famous - region Atractylodes lancea (Thunb.) DC, Pharmacogn Mag, 11, 337-344, 10.4103/0973-1296.153087, 2015.

585 Zhang, X. D., Yu, Y. G., Yang, D. F., Qi, Z. C., Liu, R. Z., Deng, F. T., Cai, Z. X., Li, Y., Sun, Y. F., and Liang, Z. S.: Chemotaxonomic variation in secondary metabolites contents and their correlation between environmental factors in Salvia miltiorrhiza Bunge from natural habitat of China, Industrial Crops and Products, 113, 335-347, 10.1016/j.indcrop.2018.01.043, 2018.

Zheng-An, S., Zhang, J.-H., and Xiao-Jun, N.: Effect of soil erosion on soil properties and crop yields on slopes in the Sichuan Basin, China, Pedosphere, 20, 736-746, 2010. 